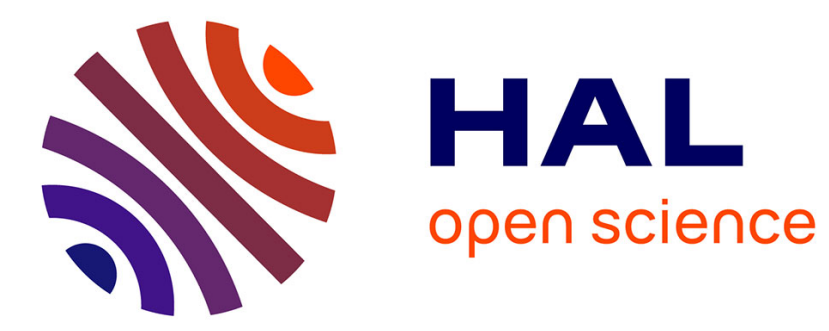

\title{
Spatiotemporal reorganization of the reading network in adult dyslexia
}

Eddy C Cavalli, Pascale Colé, Chotiga C Pattamadilok, Jean-Michel C Badier, Christelle C Zielinski, Valerie C Chanoine, Johannes C. Ziegler

\section{- To cite this version:}

Eddy C Cavalli, Pascale Colé, Chotiga C Pattamadilok, Jean-Michel C Badier, Christelle C Zielinski, et al.. Spatiotemporal reorganization of the reading network in adult dyslexia. Cortex, 2017, 92, pp.204 - 221. 10.1016/j.cortex.2017.04.012 . hal-01522706

\section{HAL Id: hal-01522706 \\ https://hal-amu.archives-ouvertes.fr/hal-01522706}

Submitted on 15 May 2017

HAL is a multi-disciplinary open access archive for the deposit and dissemination of scientific research documents, whether they are published or not. The documents may come from teaching and research institutions in France or abroad, or from public or private research centers.
L'archive ouverte pluridisciplinaire $\mathbf{H A L}$, est destinée au dépôt et à la diffusion de documents scientifiques de niveau recherche, publiés ou non, émanant des établissements d'enseignement et de recherche français ou étrangers, des laboratoires publics ou privés. 


\title{
Research report
}

\section{Spatiotemporal reorganization of the reading network in adult dyslexia}

\author{
Eddy Cavalli ${ }^{a, d, * * *}$, Pascale Cole ${ }^{a, d}$, Chotiga Pattamadilok ${ }^{b, d}$, \\ Jean-Michel Badier ${ }^{c, d}$, Christelle Zielinski ${ }^{d}$, Valérie Chanoine ${ }^{d}$ and \\ Johannes C. Ziegler ${ }^{a, d, * *}$
}

a Aix-Marseille Université and CNRS, Laboratoire de Psychologie Cognitive (UMR 7290), Fédération de recherche 3C, Marseille, France

${ }^{\mathrm{b}}$ Aix-Marseille Université and CNRS, Laboratoire Parole et Langage (UMR 7309), Aix-en-Provence, France

${ }^{c}$ Aix-Marseille Université and INSERM, Institut de Neurosciences des Systèmes, Marseille, France

d Aix-Marseille Université, Brain and Language Research Institute, Aix-en-Provence, France

\section{A R T I C L E I N F O}

\section{Article history:}

Received 5 June 2016

Reviewed 28 October 2016

Revised 5 January 2017

Accepted 12 April 2017

Action editor Jean-François

Démonet

Published online 24 April 2017

Keywords:

Dyslexics

Morphological

Semantic

Compensation

MEG

\begin{abstract}
A B S T R A C T
Developmental dyslexia is characterized by impairments in reading fluency and spelling that persist into adulthood. Here, we hypothesized that high-achieving adult dyslexics (i.e., university students with a history of dyslexia) manage to cope with these deficits by relying to a greater extent on morphological information than do non-impaired adult readers. We used magnetoencephalography (MEG) in a primed lexical decision task, in which we contrasted orthographic, morphological and semantic processing. Behavioral results confirmed that adult dyslexics did indeed rely to a greater extent on the semantic properties of morphemes than controls. In line with this, MEG results showed early morphological effects (100-200 msec) in a frontal network, which reflected the contribution of semantic processing. The same effects occurred much later in controls ( $400 \mathrm{msec}$ ). In contrast, controls showed early orthographic priming effects in posterior left inferior temporal gyrus (LITG) at around $130 \mathrm{msec}$, which were not seen in dyslexics. In the LITG, dyslexics showed only late activation of semantic and orthographic information. The present results suggest a spatiotemporal reorganization of the reading network, in which morphological information located in frontal regions is activated earlier in high-achieving adults dyslexics than controls.
\end{abstract}

(C) 2017 Elsevier Ltd. All rights reserved.

\footnotetext{
* Corresponding author. Laboratoire de Psychologie Cognitive, Aix Marseille Université, 3, place Victor Hugo, Bat 9, Case D, 13331 Marseille Cedex 3, France.

** Corresponding author. Laboratoire de Psychologie Cognitive, Aix Marseille Université, 3, place Victor Hugo, Bat 9, Case D, 13331 Marseille Cedex 3, France.

E-mail addresses: eddy.cavalli@univ-amu.fr (E. Cavalli), Johannes.ziegler@univ-amu.fr (J.C. Ziegler). 


\section{Introduction}

Developmental dyslexia is a severe disorder characterized by poor word decoding, low levels of reading fluency, and poor spelling performance (Boets et al., 2013; Demonet, Taylor, \& Chaix, 2004; Norton, Beach, \& Gabrieli, 2014; Shaywitz \& Shaywitz, 2005). It is a long-lasting deficit that persists into adulthood (Gabrieli, 2009). It has been reported that approximately $3.2 \%$ of the dyslexics in the UK manage to undertake university studies despite having dyslexia (Warmington, Stothard, \& Snowling, 2013). University students with dyslexia are an ideal population to investigate how the reading network had adapted, both spatially and temporally, to compensate for reading deficits of adults with dyslexia. Despite their welldocumented impairments in basic reading skills (i.e., poor decoding, reduced reading fluency), they seem to have coped with these deficits in such a way that reading comprehension is not (or less) affected (Deacon, Cook, \& Parrila, 2012).

It has been suggested that one of these compensatory mechanisms is reliance on contextual information and semantics (Cavalli, Casalis, El Ahmadi, Zira, Poracchia-George, \& Colé, 2016; Snowling, 2000; Stanovich, 1980). However, existing brain imaging studies do not fully support a special role for semantic processing as a compensatory mechanism in adults with dyslexia. First, while previous fMRI studies consistently found an under-activation of ventral occipito-temporal cortex in charge of orthographic processing (for meta-analyses see Paulesu, Danelli, \& Berlingeri, 2014; Richlan, 2012; Richlan, Kronbichler, \& Wimmer, 2011), only few studies found an over-activation of frontal areas that could potentially be associated with semantic processing (Brunswick, McCrory, Price, Frith, \& Frith, 1999; Salmelin, Service, Kiesilä, Uutela, \& Salonen, 1996; Shaywitz et al., 1998). Yet, the overactivation in frontal areas, such as the left inferior frontal gyrus (LIFG), has typically been interpreted in terms of an articulatory compensatory mechanism or increased effort (Richlan et al., 2011). Second, the few neuroimaging studies that specifically investigated semantic processing in dyslexia typically found weaker activation in the left middle and superior temporal cortex in dyslexics than controls (Helenius, Salmelin, Service, \& Connolly, 1999). Finally, previous studies found no evidence for faster activation of semantics in EEG or MEG. For example, Helenius et al. (1999) showed that the onset of the $\mathrm{N} 400 \mathrm{~m}$ in the left superior temporal cortex began about $100 \mathrm{msec}$ later in adults with dyslexia than controls. Similarly, Rüsseler, Becker, Johannes, and Münte (2007) found a delayed N400 in a semantic judgment task for adults with dyslexia. Taken together, at present, there is little evidence for a greater involvement of semantic areas or more efficient (faster) semantic processing in adults with dyslexia.

One interesting proposal is that adults with dyslexia might not rely on semantics per se but on morphemes, which are the smallest units of meaning (work-er, depart-ure) and provide a direct link between form and meaning. Indeed, morphologically related words share form and meaning (work, worker, working...), which significantly reduces the arbitrariness of the mapping between form and meaning (e.g., knowing that a word starts with the letter $w$ does not tell us anything about its meaning). Indeed, some evidence from university students with dyslexia suggests that some oral language skills, such as vocabulary and morphological knowledge, might function as protective factors in dyslexia (for a review, see Haft, Myers, \& Hoeft, 2016). In line with this hypothesis, Martin, Frauenfelder, and Colé (2013) showed that morphological knowledge is relatively preserved in university students with dyslexia, whereas phonological processing is clearly impaired (see also Law, Wouters, \& Ghesquière, 2015). Recently, a study showed that the dissociation between good morphological and poor phonological skills was highly predictive of reading skills in university students with dyslexia (Cavalli, Duncan, Elbro, El Ahmadi, \& Colé, 2017), which was taken to suggest that adults with dyslexia may capitalize on the semantic dimension of morphology to compensate for the well-documented phonological impairments. In addition, Elbro and Arnbak (1996) found that dyslexics tend to use a reading strategy based on morphemes rather than graphemes and phonemes. Interestingly, children with dyslexia seem to show morphological priming that is mainly due to morpho-semantic processing, whereas morphological priming in controls seems to come from morpho-orthographic processing (Quémart \& Casalis, 2013).

Research on skilled adult readers has shown that morphological processing has a specific neural signature that cannot be reduced to the joint activation of form and meaning (Beyersmann, Iakimova, Ziegler, \& Colé, 2014; Rastle \& Davis, 2008). Morphology-specific effects over and above form and meaning have been found along the ventral stream and in a vastly distributed network that includes left inferior and superior temporal gyri, LIFG and left orbitofrontal gyrus (Cavalli, Colé, Badier, Zielinski, Chanoine, \& Ziegler, 2016; Fruchter \& Marantz, 2015; Whiting, Shtyrov, \& Marslen-Wilson, 2015). In a recent MEG study using a primed lexical decision task, Cavalli et al. (2016) found evidence for a semantically driven morphological priming effect as early as $250 \mathrm{msec}$ (i.e., M250) in left superior temporal gyrus (LSTG). Both orthographic and semantic contributions to morphological facilitation were found around 350 msec (i.e., M350) along the ventral stream and in LIFG. Evidence for recombination of morphemes and semantic unification were found in orbitofrontal cortex around 450-500 msec (see also Fruchter \& Marantz, 2015).

The goal of the present study was to investigate the neural underpinnings of morphological processing in adults with dyslexia and the differences in the processing of morphological information between adults with and without dyslexia in a primed-lexical decision task. More precisely, we were interested in finding out whether high-achieving adult dyslexics rely to a greater extent on morphological processing than normal readers. We hypothesized that successful compensation (or adaptation) in university students with dyslexia is achieved through a spatiotemporal reorganization of the reading network, in which morphological information primarily processed in frontal regions is activated earlier and more strongly in this population than in controls.

To investigate the spatiotemporal dynamics of morphological processing, we recorded MEG in a primed-lexical decision task in French university students with and without dyslexia. We compared the event-related fields (ERFs) elicited by word pairs that were morphologically related, such as ourson - OURS [bear cub-bear], orthographically related, oursin - OURS [urchin-bear], semantically related peluche - OURS 
[plush-bear] and unrelated word pairs, such as gésier - OURS [gizzard-bear]. The same target word was used across the four prime conditions. The comparison between morphological and semantic priming makes it possible to assess the "orthographic part" of morphological facilitation (i.e., the $\mathrm{M}+\mathrm{O}+$ effect) because both primes are equated for overlap in meaning but only morphological primes share orthography with the target. The comparison between morphological and orthographic primes makes it possible to assess the "semantic part" of morphological facilitation (i.e., the $\mathrm{M}+\mathrm{S}+$ effect) because both primes are equated for overlap in orthography but only morphological primes share meaning with the target. In each region of interest (ROI), the $\mathrm{M}+\mathrm{O}+$ and $\mathrm{M}+\mathrm{S}+$ effects were contrasted with pure orthographic or pure semantic effects to further constrain the interpretation of the joint effects of morphology and orthography or morphology and meaning.

We focused our MEG analyses on the left inferior and superior fronto-occipital networks involved in orthographic, morphological and lexicosemantic processing in reading (Jobard, Crivello, \& Tzourio-Mazoyer, 2003). The ROIs were: (1) the left middle fusiform gyrus (FG) and the posterior part of the left inferior temporal gyrus (LITG), two regions in charge of orthographic processing that are typically under-activated in adults with dyslexia (Paulesu et al., 2014; Richlan, 2012; Richlan et al., 2011). These areas are also involved in the early decomposition based on morphological properties of complex words in skilled adult readers (Solomyak \& Marantz, 2010); (2) the pars triangularis and pars orbitalis of the LIFG that is sometimes over-activated in adults with dyslexia (Richlan et al., 2011; Shaywitz et al., 1998). These Broca areas are activated during the processing of semantics (Friederici, 2011; Price, 2012) and morphology (Bozic, Marslen-Wilson, Stamatakis, Davis, \& Tyler, 2007; Whiting et al., 2015; Zou, Packard, Xia, Liu, \& Shu, 2016) in skilled adult readers; (3) the left orbitofrontal gyrus, which has been shown to play a role in morpho-semantic processing and the recombination of morphemes (Cavalli et al., 2016; Fruchter \& Marantz, 2015); (4) and finally the LSTG which has been shown to be involved in morphological decomposition and lexical access (Cavalli et al., 2016; Fruchter \& Marantz, 2015; Whiting et al., 2015). This region is also activated in adults with dyslexia during semantic processing (Helenius et al., 1999). We hypothesized to find spatiotemporal differences in processing morphological information between high achieving adult dyslexics and skilled readers. More specifically, we expected to see morphological priming effects in the frontal network earlier in adult dyslexics than in controls for whom such effects had been reported around $350 \mathrm{msec}$ (M350). In contrast, we expected to see orthographic and morpho-orthographic priming effects in the posterior occipito-temporal network later in adult dyslexics than skilled readers for whom such effects had been found in the time window of the M130/M170.

\section{Materials and methods}

\subsection{Participants}

Twenty adults with dyslexia and 20 skilled readers participated in the present study and received $€ 50$ for their participation. All participants were university students and native speakers of French. They were recruited at AixMarseille University (France) from a wide variety of academic programs (i.e., within each group, $55 \%$ of the participants were enrolled in social science programs and $45 \%$ were enrolled in science programs). Dyslexic and skilled readers were matched on gender (11 females, 9 males for each groups), chronological age $[$ mean $=23.9$ years; $\mathrm{SD}=5.2 ; \mathrm{t}(38)=.40$, $p>.80$ ], educational level $[$ mean $=3.1 ; \mathrm{SD}=1.7 ; \mathrm{t}(38)=.11$, $p>$.90], nonverbal IQ [ mean $=49.0$; $\mathrm{SD}=4.1 ; \mathrm{t}(38)=.38, p>.90$ ], and verbal IQ as measured by the EVIP vocabulary test $[$ mean $=116 ; \mathrm{SD}=7.1 ; \mathrm{t}(38)=.08, p>.90 ;$ French PPVT-R; Dunn, Thériault-Whalen, \& Dunn, 1993]. Two dyslexic participants were excluded from the MEG analyses because of interference from a dental implant or excessive motion artefacts.

All university students with dyslexia had a formal diagnosis of dyslexia established by a national reference center for the diagnosis of learning disabilities (Centre de Référence des Troubles d'Apprentissages, Hôpital Salvator, Marseille). All dyslexics had been diagnosed during primary school and participated in various remediation programs for an average of 5.8 years $(S D=.45)$. All of them reported having experienced major difficulties in learning to read in childhood. Moreover, all dyslexics were monolingual native speakers of French, they did not have any known neurological or psychiatric disorders, they reported normal or corrected-to-normal hearing or vision, they had a nonverbal IQ within the normal range (>25th centile, Raven's matrices; Raven, Court, \& Raven, 1995), and they obtained a reading score that was at least two standard deviations below the mean of the controls. The reading score was obtained using the Alouette reading test (Lefavrais, 2005), a standardized reading test for French, which is the most widely used diagnostic test for dyslexia in France (Bertrand, Fluss, Billard, \& Ziegler, 2010; see also Cavalli, Colé, Leloup, Sprenger-Charolles, Poracchia-George, \& El Ahmadi, 2017, for a recent validation of this test in adults with dyslexia). Participants in the control group were monolingual native speakers of French, they had normal literacy skills with no previous history of any learning disability and a nonverbal IQ in the normal range. The two groups differed significantly on the mean reading score [DYS mean $=371.4 ; \mathrm{SD}=78.5$; SR mean $=549.7 ; \mathrm{SD}=62.6 ; \mathrm{t}(37)=-10.9, p<.001]$.

In addition, phonological skills were assessed in both groups through pseudoword reading, phonemic awareness, and phonological short-term memory (STM) tasks. These tasks were taken from a computerized battery for the assessment of reading and reading-related skills (SprengerCharolles, Colé, Béchennec, \& Kipffer-Piquard, 2005). Results are displayed in Table 1 . They confirm that adults with dyslexia performed significantly worse than skilled readers (all $p s<.001)$ in all phonological tasks.

\subsection{Design and stimuli}

The stimuli consisted of 48 quadruplets of prime-target word pairs (192 trials). In each quadruplet, the same target word was paired with four different primes corresponding to the four experimental conditions. Word pairs were either morphologically related [ourson - OURS (bear cub-bear)], orthographically related [oursin - OURS (urchin-bear)], 
Table 1 - Mean scores (and standard deviations) for both dyslexic and skilled readers on tests of reading pseudowords, phonemic awareness, and phonological short-term memory (STM).

\begin{tabular}{clll}
\hline & & $\begin{array}{c}\text { Dyslexic } \\
\text { readers }\end{array}$ & $\begin{array}{l}\text { Skilled } \\
\text { readers }\end{array}$ \\
\hline Pseudoword & Error rate (\%) & $10.1(7.5)^{* * *}$ & $2.6(2.4)$ \\
reading & Response time (msec) & $1284(560)^{* * *}$ & $631(118)$ \\
Phonemic & Error rate (\%) & $10.9(8.6)^{* * *}$ & $2.0(2.8)$ \\
awareness & Response time (sec) & $30.2(8.6)^{* * *}$ & $16.1(4)$ \\
Phonological & Accuracy (span) & $4.31(.8)^{* * *}$ & $5.3(.5)$ \\
STM & Response time (sec) & $65.7(25.2)^{* * *}$ & $46.7(4.5)$ \\
\hline${ }^{* * *} p<.001$. & & & \\
\hline
\end{tabular}

semantically related [peluche - OURS (plush-bear)], or unrelated [gésier - OURS (gizzard-bear)]. Prime words were presented in lower case, whereas target words were presented in upper case. All target words were mono-morphemic and had a mean frequency of $58.6(\mathrm{SD}=102.39)$ per million according to LEXIQUE, a mean length of $5.10(\mathrm{SD}=1.07)$ and a mean number of syllable of $1.60(\mathrm{SD}=.76)$. Table 2 presents the characteristics of the primes in the four experimental conditions. In the morphological condition, each prime and target belonged to the same morphological family and shared the same stem. Across the four conditions, the primes were matched in terms of frequency (all $p>.30$ ), number of letters (all $p>.30$ ), and number of syllables (all $p>.30$ ). In order to control for the semantic similarity between primes and targets across the morphological and semantic conditions, we calculated the strength of the cosine similarity between primes and targets using latent semantic analysis (LSA, http://lsa.colorado.edu/). There was no difference $(p>.63)$ in semantic association strength between the morphological $(M=.28 ; \mathrm{SD}=.18)$ and the semantic conditions $(M=.24 ; \mathrm{SD}=.17)$. In order to control for the orthographic overlap between the morphological and the orthographic conditions, targets and primes shared on average the first 3.7 letters $(\mathrm{SD}=1.07)$ in the morphological condition, and they shared on average the first 3.5 letters $(\mathrm{SD}=.85)$ in the orthographic condition $(p>.34)$.

For the purpose of the lexical decision task, 48 pseudoword targets were included. They were formed by changing two letters from real words. Each pseudoword was associated with four word primes, which were matched to the primes of the word condition in terms of frequency $(M=9.8$; $S D=2.89)$, number of letters $(M=6.9 ; S D=.29)$, and number of syllables $(M=2 ; S D=0)$. This led to a total of 192 word-pseudoword pairs.

The stimuli were divided into four lists, such that each target word and pseudoword would appear only once in each list. Each list contained 48 word targets (twelve per condition) and 48 pseudoword targets. Stimuli were presented in a pseudo-random order (with a maximum of two repetitions of the same priming condition). The order of presentation of the four lists was counterbalanced across subjects using a Latin square design. The experiment was preceded by a practice session consisting of 10 trials.

\subsection{Experimental procedure}

Presentation ${ }^{\circledR}$ software (http://neurobs.com/) was used to display the stimuli and to control the experiment. MEG signals were recorded while the subject was lying in a horizontal position in order to reduce movement artefacts. The stimuli were projected using a video projection onto a screen that was located at $\sim 42 \mathrm{~cm}$ away from the participant. The stimuli were displayed in black 16-point Courier New (maximal width of $2.24^{\circ}$ and maximal height of $.41^{\circ}$ ). Each trial consisted of a fixation cross appearing in the center of the screen for $500 \mathrm{msec}$, a blank for $50 \mathrm{msec}$, and a prime for $200 \mathrm{msec}$ (see Fig. 1). This prime duration was used because it has previously been shown that semantic influences on morphological priming are more prominent when the prime is partially or fully visible (Beyersmann et al., 2014). Target words were presented $50 \mathrm{msec}$ after the offset of the prime (Stimulus Onset Asynchrony $=250 \mathrm{msec}$ ), until the subject's response. The participant's responses were recorded using a LUMItouch ${ }^{\circledR}$ optical response keypad. Participants were instructed to press a button with the right index finger when the target was a word and with the right thumb when the target was not a word. The inter-trial interval was $1900 \mathrm{msec}$. Note that no jitter was introduced between trials, which means that there was absolutely no ambiguity as to when primes and targets occurred on the screen. One potential implication is that participants could perfectly adapt to the timing of task events, which might increase strategic processes but also reduce taskirrelevant noise (e.g., lapses of attention). Finally, participants were instructed to move as little as possible and avoid eyeblinks during the trials.

\subsection{MEG data acquisition}

Continuous MEG of cerebral activity was recorded in a magnetically shielded room using a whole head, 248-channel biomagnetometer system (4D Neuroimaging, San Diego, CA, USA). The sampling rate was $2034.5 \mathrm{~Hz}$. In order to determine the location of the head with respect to the MEG array, five coils were fixed on the subject's head. The position of these coils as well as the surface of the head was digitized with a 3-D digitizer (Polhemus Fastrack, Polhemus Corporation,

Table 2 - Characteristics of primes across the different prime conditions.

\begin{tabular}{lcccc}
\hline & \multicolumn{4}{c}{ Type of priming } \\
\cline { 2 - 5 } & Morphological & Orthographic & Semantic & Unrelated \\
\hline Frequency & $9.52(15.51)$ & $10.09(12.38)$ & $12.33(11.81)$ & $9.53(7.43)$ \\
Number of letters & $7.00(1.12)$ & $6.85(1.07)$ & $6.60(1.74)$ & $7.00(.92)$ \\
Number of syllables & $2.10(.37)$ & $2.06(.52)$ & $2.00(.74)$ & $2.12(.33)$ \\
\hline
\end{tabular}




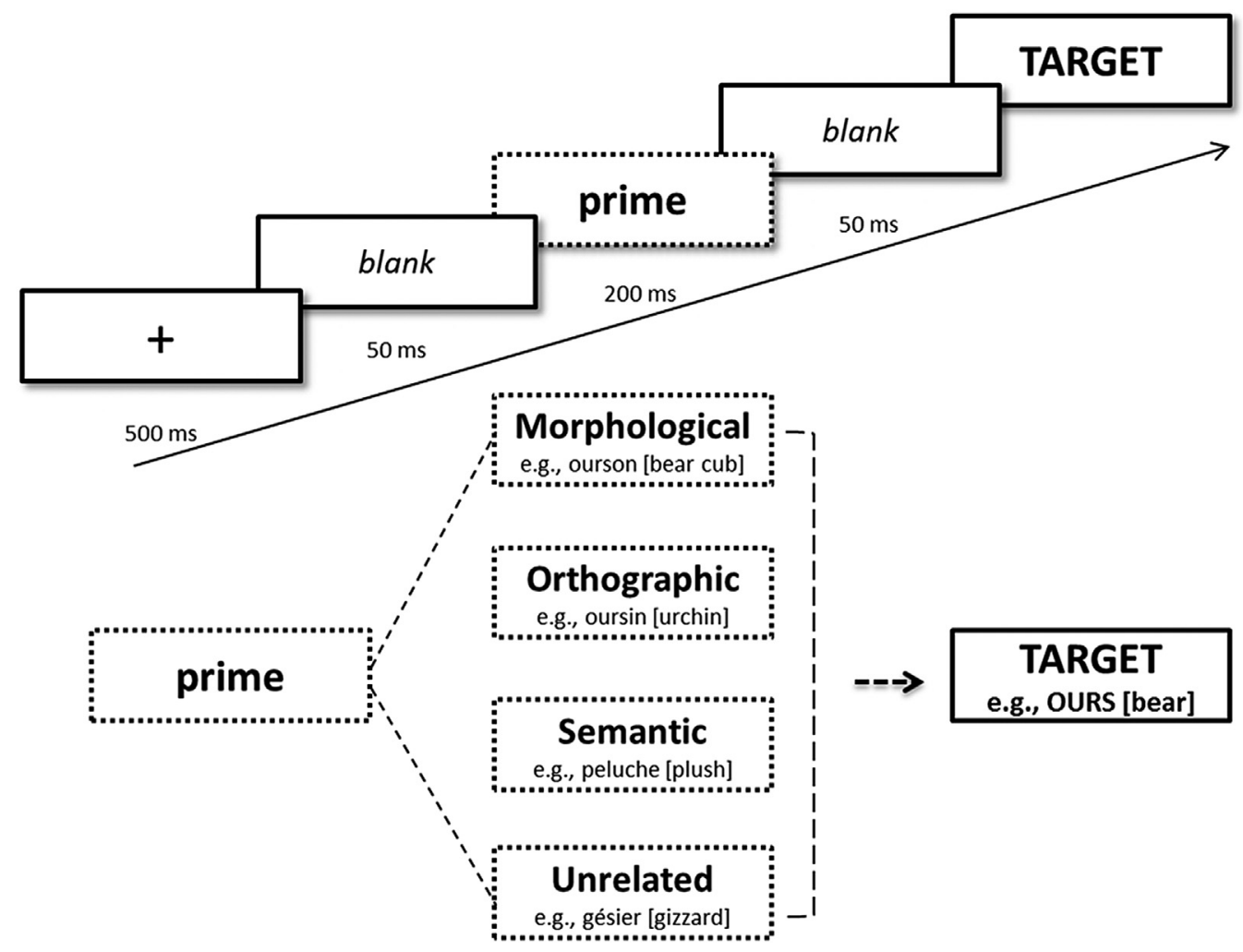

Fig. 1 - Representation of the experimental primed lexical decision task.

Colchester, VT, USA). The surface digitization served as a measure of the head shape that was used in subsequent analyses (see below).

\subsection{MEG analysis and statistical methodology}

Data pre-processing was performed using Anywave software (http://meg.univ-amu.fr/wiki/Anywave; Colombet, Woodman, Bénar, \& Badier, 2015) for the visual rejection of channels that showed excessive noise, muscle, or SQUID jump artifacts. All major analyses were performed using the Fieldtrip toolbox in Matlab 8.1 (http://fieldtrip.fcdonders.nl/; Oostenveld, Fries, Maris, \& Schoffelen, 2011).

Pre-processing and source reconstruction were performed for each participant, separately. Data were filtered by a bandpass filter in the range of $.5-300 \mathrm{~Hz}$ (Butterworth IIR filter, $2^{\text {nd }}$ order filter and zero-phase forward and reverse filter). An independent component analysis (runica algorithm; learning rate .1\%; 248 components) was performed on the continuous data to identify and remove the heartbeat and blink artifacts. Epochs for each trial were extracted from the continuous data between -500 and $1000 \mathrm{msec}$ relative to target stimulus onset. These extracted trials were again visually inspected to remove remaining noisy trials. All subsequent analyses were performed on correct "yes" trials only. Event-Related Fields (ERFs) were then computed by averaging for each channel the trials that corresponded to the same experimental condition (morphological, orthographic, semantic, unrelated and pseudoword). The -500 to -300 interval, that is, the interval just before the onset of the prime, was used for baseline correction.

Sensor-level analysis was conducted on magnetometers $\left(10^{-14} \mathrm{~T}\right)$. After the rejection of artefacts, 222 sensors remained for the sensor-level analysis. Sensors were divided into 9 groups corresponding to the anterior (left, middle, right), central (left, middle, right) and posterior (left, middle, right) locations. ERFs were averaged within each group of sensors for each participant and condition and then analyzed in the critical MEG time windows for word recognition proposed by Pylkkänen and Marantz (2003). The time windows used were the M170 (150-200 msec), the M250 (200-300 msec), the M350 (300-420 msec) and the post-M350 (420-500 msec). ANOVAs were computed separately for each time window of interest. ANOVAs always included 2 Groups (Dyslexics; Skilled readers) as a between-subject factor and 4 Conditions (morphological; orthographic; semantic; unrelated) and 9 groups of Sensors (anterior left; anterior mid; anterior right; central left; central mid; central right; posterior left; posterior mid; posterior right) as within-subject factors. Post-hoc comparisons, corrected using the False Discovery Rate (FDR; Benjamini \& Hochberg, 1995), were used to determine the origin of significant interactions.

For source reconstruction, trials were filtered by a low-pass filter with a cut-off frequency of $25 \mathrm{~Hz}$ and then resampled to $200 \mathrm{~Hz}$. The head shape of each participant was fit to a MNI Colin27 template (Holme et al., 1998) using the co-registration function of SPM8 (Wellcome Department of Imaging Neuroscience, University College London, www.fil.ion.ucl.ac.uk). 
The dipole source locations were defined on the Colin27 template by the node coordinates of a 3D-uniform rectangular grid with a spacing of $10 \mathrm{~mm}$. This resulted in 2127 sources that are inside the template brain. This template grid was then transformed to fit each subject's head shape using the same transformation as above (Harpaz, Lavidor, \& Goldstein, 2013), which allowed us to perform group analyses using the same source space.

For the MEG forward calculation, we used a method based on a semi-realistic head shape model developed by Nolte (2003), which was implemented in FieldTrip. Thereafter, the inverse problem was solved to estimate the magnetic intensity variations at each dipole that best explained the MEG measurements. Each node of the grid was associated with a triplet of orthogonal dipoles (one per direction) giving a volume model of unconstrained sources. To solve the inverse problem, a Linear Constrained Minimum Variance beamformer (LCMV; see van Been, van Drongelen, Yuchtman, \& Suzuki, 1997) was used. This makes it possible to reconstruct the time courses of the 2127 dipole triplets. The three time courses of each triplet were reduced to a time-course of a single generator using Singular Value Decomposition.

LCMV is known to amplify the variance of the sources in deeper dipole locations. In order to correct for that bias, the source signals were normalized using a $z$-transformation with respect to a pre-stimulus interval between -500 and $-300 \mathrm{msec}$ (i.e., a $200 \mathrm{msec}$ interval before the onset of the prime). This effectively corrects for the bias, because it can be assumed that the same bias is present in the pre-stimulus interval. Finally, because primes differed across conditions but targets were identical across conditions, we corrected for differences that were present before the onset of the target by subtracting the mean value of the normalized signal in the pre-target interval [ -250 to 0] $\mathrm{msec}$ from the normalized source signal of each generator.

To further constrain our analyses in source space, we selected six anatomically-defined ROIs within the left hemisphere. The left middle FG and posterior part of the LITG were selected to tap orthographic and morpho-orthographic processes (VWFA). The LIFG including both the pars triangularis and orbitalis were selected to tap semantic and morphosemantic processing. The left orbitofrontal gyrus was selected to tap semantic integration and morphological recombination stages. The LSTG was selected to tap morphological decomposition, semantic processing and lexical access. To identify the generators that correspond to each ROI, we referred to the Automated Anatomical Labeling (AAL) atlas (Tzourio-Mazoyer et al., 2002) in Colin27 space. The source signals that fell within a selected ROI were then averaged for each by participants and conditions, separately. Finally, we computed paired t-tests as a statistical analysis and the resulting $t$-values were corrected for multiple comparisons over the time period [0 to 650] msec using the clusterbased permutation method proposed by Maris and Oostenveld (2007). This statistical test was performed by computing a $p$ value under the permutation distribution and comparing it with some critical $\alpha$-level. The procedure consisted of performing a non-parametrical permutation test on each time point between two experimental conditions during the whole time period of [0 to 650] msec. The $p$-values resulting for each cluster (i.e. the maximum cluster-level statistic) was compared to the results of the same procedure repeated on 10,000 random permutations.

\section{Results}

For both reaction times (RTs) and MEG analyses, we performed comparisons across experimental conditions to investigate different processes: the global effect of morphological overlap (morphological us unrelated), the pure effect of orthographic overlap (orthographic vs unrelated) and the pure effect of semantic overlap (semantic us unrelated). With respect to more specific effects of morphology, the contrast between morphological and orthographic priming conditions allowed us to investigate morphologial priming when orthographic overlap was partialled out $(\mathrm{M}+\mathrm{S}+$ effect) and the contrast between morphological and semantic priming conditions allowed us to investigate morphological priming when semantic overlap was partialled out $(\mathrm{M}+\mathrm{O}+$ effect).

\subsection{Behavioral results}

Table 3 presents the reaction times (RTs) and error rates for the four conditions and the two groups. We ran repeated measure ANOVAs on RTs for correct responses only and error rates with Prime condition (morphological, orthographic, semantic, unrelated) as a within-subjects factor and Group (dyslexics us skilled readers) as a between-subjects factor. After removing extreme values (RTs $>4000 \mathrm{msec}$, less than $.3 \%$ ), all RTs were log-transformed in order to normalize the distribution (Mauchly's sphericity, $p=.40$ ).

The ANOVA on RTs yielded a significant effect of Prime Condition $\left[F(3,111)=40.73 ; p<.001 ; \eta^{2}=.524\right]$, a significant effect of Group $\left[F(3,37)=6.76 ; p=.013 ; \eta^{2}=.154\right]$, and a significant interaction between Condition $\times$ Group $\left[F(3,111)=4.63 ; p=.004 ; \eta^{2}=.111\right]$. We conducted a set of pairwise comparisons correcting the level of significance of each test using the False Discovery Rate (FDR; Benjamini \& Hochberg, 1995). The comparisons indicated a significant effect of morphological priming for the two groups $(p<.001$; less than the BH threshold $q=.004$ ) and a significant interaction $\left[F(1,37)=4.8 ; p=.03 ; \eta^{2}=.115\right]$ showing that the morphological priming effect was larger for dyslexics $(-81 \mathrm{msec})$ than for skilled readers $(-67 \mathrm{msec})$. We also found a significant effect of semantic priming for dyslexics $(p<.001$; less than the $\mathrm{BH}$ threshold $q=.008)$ and for skilled readers $(p=.026$; less than the $\mathrm{BH}$ threshold $q=.03)$ but the interaction was only marginally significant $\left[F(1,37)=3.15 ; p=.08 ; \eta^{2}=.079\right]$ reflecting a somewhat larger effect for dyslexics (-48 $\mathrm{msec})$ than skilled readers $(-40 \mathrm{msec})$. No significant effect of orthographic priming was found for dyslexics $(p=.950)$ or skilled readers $(p=.258)$.

With respect to the specific morphological effects, there was a significant difference between the morphological and semantic priming conditions $(\mathrm{M}+\mathrm{O}+$ effect) for dyslexics $(p<.001$; less than the BH threshold $q=.01)$ and for skilled readers $(p<.01$; less than the $\mathrm{BH}$ threshold $q=.03)$ but no interaction $[F(1,37)=.32 ; p=.57]$ between dyslexics $(-33 \mathrm{msec})$ and skilled readers $(-27 \mathrm{msec})$. In addition, there was a 
Table 3 - Mean lexical decision reaction times (in msec) and percent errors for each prime condition and for both groups. Standard deviations in parentheses.

\begin{tabular}{|c|c|c|c|c|c|c|}
\hline & \multicolumn{3}{|c|}{ Reaction times (msec) } & \multirow[b]{2}{*}{$\overline{\text { Main effects }}{ }^{a}$} & \multicolumn{2}{|c|}{ Error rates (\%) } \\
\hline & Dyslexic readers & Main effects ${ }^{a}$ & Skilled readers & & Dyslexic readers & Skilled readers \\
\hline Morphological & $792(224)$ & $-81 \mathrm{msec}^{* * *}$ & $646(155)$ & $-67 \mathrm{msec}^{* * *}$ & $1.5(1.9)$ & $1.0(1.2)$ \\
\hline Orthographic & $854(233)$ & $-19 \mathrm{msec}$ & $692(169)$ & $-21 \mathrm{msec}$ & $1.5(2.0)$ & $1.2(1.8)$ \\
\hline Semantic & $825(203)$ & $-48 \mathrm{msec}^{* * *}$ & $673(152)$ & -40 msec $^{*}$ & $1.9(2.0)$ & $1.3(1.9)$ \\
\hline Unrelated & $873(240)$ & & 713 (195) & & $.7(1.2)$ & $2.0(2.9)$ \\
\hline Pseudowords & $1039(370)$ & & 766 (192) & & $1.8(2.3)$ & $1.6(1.5)$ \\
\hline
\end{tabular}

significant difference between the morphological and the orthographic priming conditions ( $\mathrm{M}+\mathrm{S}+$ effect) for the two groups $(p<.001$; less than the $\mathrm{BH}$ threshold $q=.01)$ and a significant interaction $\left[F(1,37)=14.8 ; p<.001 ; \eta^{2}=.282\right]$ showing that the magnitude of $\mathrm{M}+\mathrm{S}+$ effect was larger for dyslexics (-62 msec) than for skilled readers (-46 msec).

On the error data, the ANOVA revealed no significant effect of Prime Condition $[F(3,111)=.45 ; p=.70]$, no significant effect of Group $[F(1,37)=.002 ; p=.96]$ and no significant interaction between Condition $\times$ Group $[F(3,111)=3.69 ; p<.05$; greater than the BH-corrected threshold $q>.004]$.

\subsection{MEG results}

\subsubsection{Sensor-based analyses}

The 4D-magnetometers layout (Fig. 2) presents the nine groups of sensors used for the sensor-based analysis on the ERFs (anterior, central, posterior $\times$ left, middle, right). Table 4 presents the main effects of Group (G), Sensors (S), and Condition (C) as well as their interactions, separately for each critical time window. More detailed statistical results, including the relevant contrasts for each group of sensors and for each time window, can be found in the Supplementary Materials (Tables S1 to S3 for the M250, M350 and Post-M350, respectively).

For the M170 time window (150-200 msec), results of $2 \times 4$ $\times 9$ ANOVA yielded a significant effect of Sensor $\left[F(8,288)=31 ; p<.001 ; \eta^{2}=.46\right]$ and a significant interaction between Sensor $\times$ Group $\left[F(8,864)=2.6 ; p=.04 ; \eta^{2}=.10\right]$. Separate ANOVAs for each group of sensors showed a reduced activation (priming effect) for Dyslexics $\left(-.8010^{-14} \mathrm{~T}\right.$, $\mathrm{SD}=1.0)$ compared to Skilled readers $\left(-4.1410^{-14} \mathrm{~T}, \mathrm{SD}=.5\right)$ only in the Anterior Left (1) sensors $(p=.02)$. None of the other comparisons revealed significant effects in any of the group of sensors.

For the M250 time window (200-300 $\mathrm{msec})$, the ANOVAs yielded a significant effect of Sensor $[F(8,288)=34.2 ; p<.001$; $\left.\eta^{2}=.46\right]$, and a significant interaction between Sensor $\times$ Condition $\left[F(24,864)=1.8 ; p<.01 ; \eta^{2}=.09\right]$. For each group of sensors, we conducted a set of pairwise comparisons $(\mathrm{M}+$ effect, $\mathrm{M}+\mathrm{S}+$ effect, $\mathrm{M}+\mathrm{O}+$ effect, $\mathrm{O}+$ effect, $\mathrm{S}+$ effect). Full contrasts can be found in Table S1 of the Supplementary Materials. They showed significant $\mathrm{M}+$ effect in the Anterior Left ( 1$)$ sensors $(p=.002)$ and in the Posterior Left (7) sensors $(p=.006)$, and a significant $\mathrm{M}+\mathrm{O}+$ effect in the Posterior Left (7) sensors $(p=.02)$.
For the M350 time window (300-420 msec), the ANOVAs yielded a significant effect of Sensor $[F(8,288)=10.4 ; p<.001$; $\left.\eta^{2}=.46\right]$ and a significant interaction between Sensor $\times$ Condition $\left[F(24,864)=5.4 ;<.001 ; \eta^{2}=.13\right]$. Full contrasts can be seen in Table S2. They showed significant global and specific morphological priming effects in the bilateral Anterior (1 and 3 ) and Posterior (7 and 9) sensors (all $p<.05)$.

For the Post-M350 time window (420-500 msec), the ANOVAs yielded a significant effect of Sensor $[F(8,288)=6.8$; $\left.p<.001 ; \eta^{2}=.46\right]$, a significant main effect of Condition $\left[F(3,108)=2.7 ; p<.01 ; \eta^{2}=.07\right]$ and significant interaction between Sensor $\times$ Group $\left[F(8,288)=5 ; p<.01 ; \eta^{2}=.12\right]$. Separate ANOVAs for each group of sensors showed a reduced activation (priming effect) for Dyslexics $\left(-.9510^{-14} \mathrm{~T}, \mathrm{SD}=.8\right)$ compared to Skilled readers $\left(-2.8210^{-14} \mathrm{~T}, \mathrm{SD}=.8\right)$ in the Anterior Left (1) sensors $(p=.02)$ and stronger activation for Dyslexics $\left(-5.7210^{-14} \mathrm{~T}, \mathrm{SD}=1.1\right)$ compared to Skilled readers $\left(-3.0510^{-14} \mathrm{~T}, \mathrm{SD}=1.0\right)$ in the Posterior Left (7) sensors. The ANOVAs also yielded a significant interaction between Sensor $\times$ Condition $\left[F(24,864)=5.8 ; p<.001 ; \eta^{2}=.13\right]$. Full contrasts can be found in Table S3. They showed significant global and specific morphological priming effects in the bilateral Anterior (1 and 3) and Posterior (7 and 9) sensors (all $p<.05$ ), the $\mathrm{S}+$ effect was significant in the bilateral Anterior (1 and 3 ) and Posterior Left $(7)$ sensors (all $p<.05$ ) and the $\mathrm{O}+$ effect was significant only in the Left Posterior (7) sensors $(p<.01)$.

\subsubsection{Source-space analyses}

For the MEG source-space analyses, we selected a priori defined ROIs including the left inferior frontal regions, the left occipito-temporal regions and the LSTG. However, to validate the choice of these ROIs and to make sure that we have not missed other regions with specific effects of morphology, we also conducted a data-driven analyses on the whole brain. Detailed results of this analysis are presented in the Supplementary Materials for the $\mathrm{M}+$ effect (Fig. S1), the $\mathrm{M}+\mathrm{O}+$ effect (Fig. S2) and the $\mathrm{M}+\mathrm{S}+$ effect (Fig. S3). This data-driven analysis clearly validated the choice of our ROIs (i.e., most of the specific morphological effects were indeed present in these regions) but also showed the involvement of two other ROIs namely the anterior part of the left FG and the LITG (see Fig. S4 and S5).

\subsubsection{Left inferior frontal regions}

Fig. 3 displays the time-course of average activation within the LIFG and left orbitofrontal gyrus, both for dyslexic and skilled 


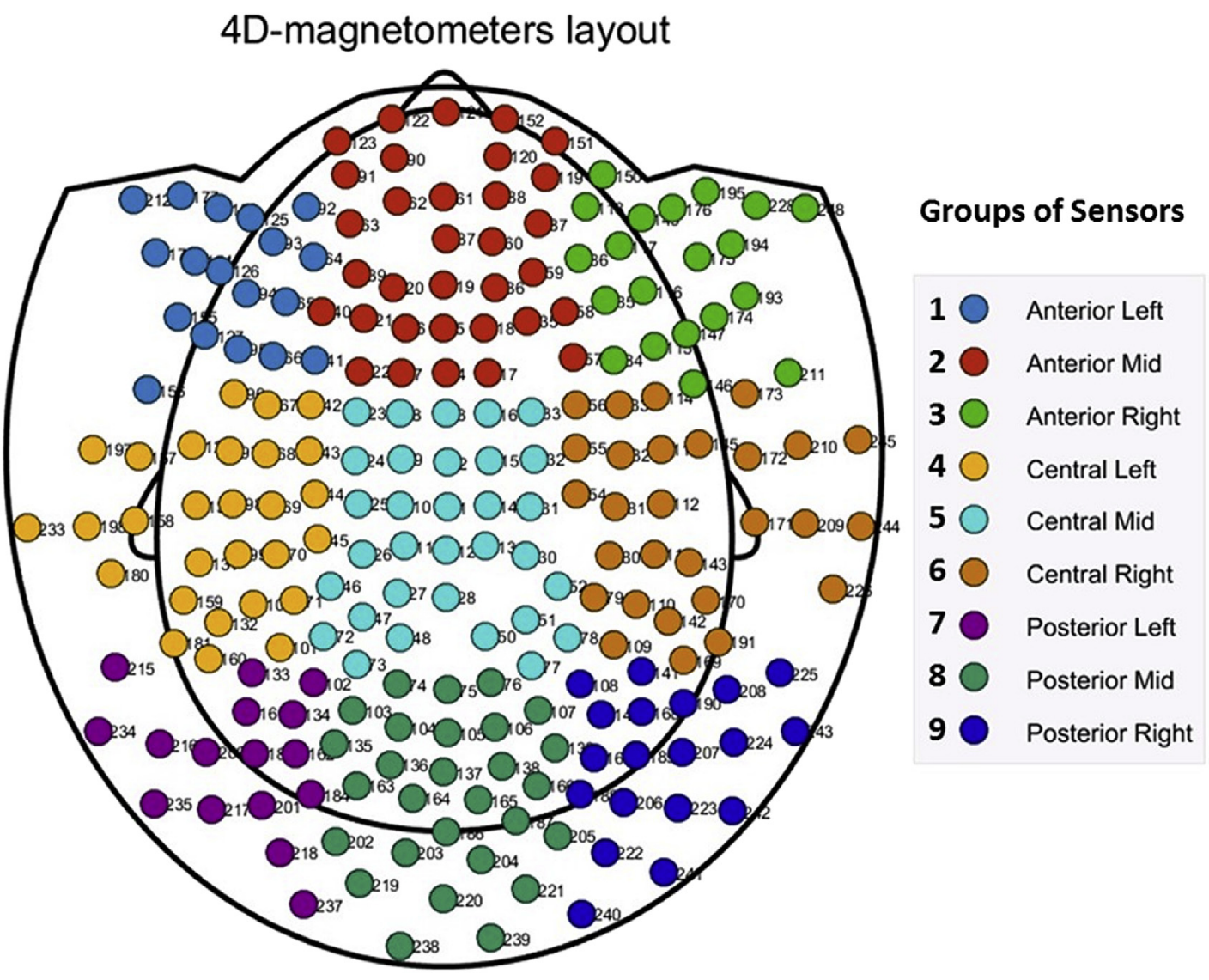

Fig. 2 - 4D-Magnetometers Layout. Groups of Sensors (after artefact rejection) used to visualize the Evoked Response Fields (ERFs). ERFs have been averaged within each of the 9 groups of sensor. Groups of sensor correspond to $1=$ Anterior Left; 2 = Anterior Mid; $3=$ Anterior Right; $4=$ Central Left; $5=$ Central Mid; $6=$ Central Right; $7=$ Posterior Left; $8=$ Posterior Mid; 9 = Posterior Right.

Table 4 - Results of an ANOVA of the sensor-level data with Group (Dyslexics, Controls), Condition (Morphology, Semantics, Orthography, Unrelated) and Sensors (anterior left, middle, right; central left, middle, right; posterior left, middle, right) as factors.

\begin{tabular}{|c|c|c|c|c|c|}
\hline 150-200 msec M170 & $F$ & $p$ & 300-420 msec M350 & $F$ & $p$ \\
\hline G & .8 & .35 & G & .1 & .95 \\
\hline S & 31.0 & $<.001$ & $\mathrm{~S}$ & 10.4 & $<.001$ \\
\hline C & 1.1 & .32 & C & .6 & .74 \\
\hline $\mathrm{S} \times \mathrm{G}$ & 2.6 & .04 & $\mathrm{~S} \times \mathrm{G}$ & .5 & .67 \\
\hline $\mathrm{C} \times \mathrm{G}$ & .6 & .56 & $C \times G$ & 1.0 & .35 \\
\hline $\mathrm{S} \times \mathrm{C}$ & 1.0 & .34 & $\mathrm{~S} \times \mathrm{C}$ & 5.4 & $<.001$ \\
\hline $\mathrm{S} \times \mathrm{C} \times \mathrm{G}$ & .3 & .99 & $\mathrm{~S} \times \mathrm{C} \times \mathrm{G}$ & .3 & .99 \\
\hline 200-300 msec M250 & $F$ & $p$ & $420-500$ msec Post-M350 & $F$ & $p$ \\
\hline G & .5 & .94 & G & .9 & .34 \\
\hline S & 34.2 & $<.001$ & $\mathrm{~S}$ & 6.8 & $<.001$ \\
\hline C & 1.0 & .43 & C & 2.7 & .006 \\
\hline$S \times G$ & .1 & .94 & $\mathrm{~S} \times \mathrm{G}$ & 5.0 & .003 \\
\hline $\mathrm{C} \times \mathrm{G}$ & .5 & .64 & $\mathrm{C} \times \mathrm{G}$ & 1.2 & .30 \\
\hline $\mathrm{S} \times \mathrm{C}$ & 1.8 & .01 & $\mathrm{~S} \times \mathrm{C}$ & 5.8 & $<.001$ \\
\hline $\mathrm{S} \times \mathrm{C} \times \mathrm{G}$ & 1.0 & .40 & $\mathrm{~S} \times \mathrm{C} \times \mathrm{G}$ & .7 & .80 \\
\hline
\end{tabular}

Note. Significant effects are printed in bold italics, and exact level of significance are indicated except when $p$ values were inferior to .001 (<.001). $\mathrm{G}=$ Group (2); $\mathrm{S}=$ Sensors (9); C = Condition (4). 


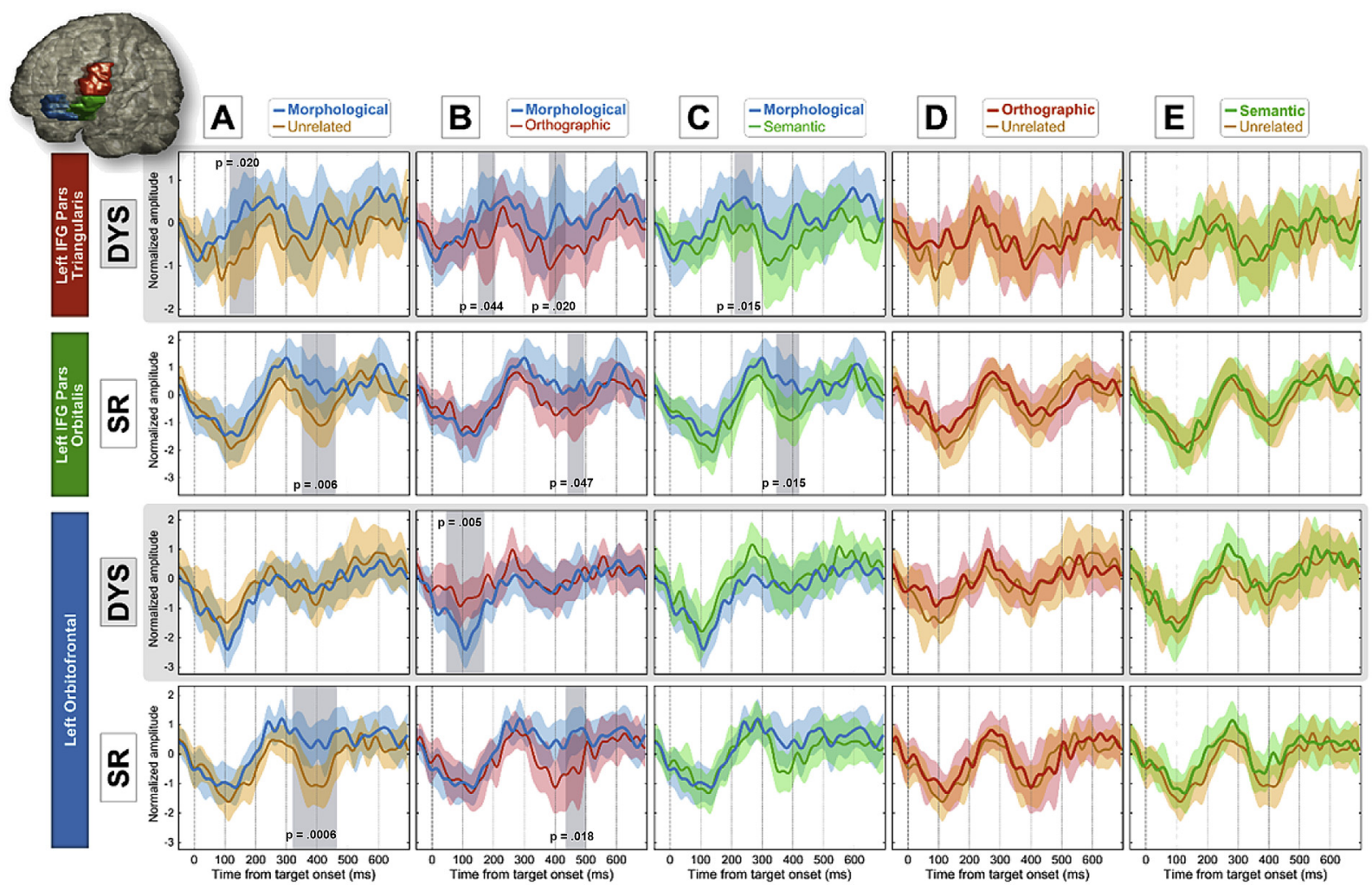

Fig. 3 - Mean source signal activity in the left inferior frontal ROIs. Red box (top) corresponds to the left inferior frontal gyrus (IFG) pars triangularis (30 dipoles), Green box (middle) corresponds to the left IFG pars orbitalis (14 dipoles) and Blue box (bottom) corresponds to the left orbitofrontal gyrus (13 dipoles). (A) Global morphological priming effect, M+, and 95\% Confidence Interval (see Allen, Erhardt, \& Calhoun, 2012) for dyslexic readers (DYS) and for skilled readers (SR), (B) M+S+ effect, (C) $\mathrm{M}+\mathrm{O}+$ effect, (D) pure orthographic priming effect, $\mathrm{O}+$, and $(\mathrm{E})$ pure semantic priming effect, $\mathrm{S}+$. The significant time windows are presented in vertical gray band with the corresponding $p$ value after correction for multiple comparisons (nonparametric permutation test).

readers. As concerns the LIFG, the results showed a dissociated pattern of activation on both spatial and temporal dimensions: significant priming effects (footnote ${ }^{1}$ ) were only found in the pars triangularis (BA45) for dyslexics and in the pars orbitalis (BA47) for skilled readers. A condition $\times$ group mixed design ANOVA yielded a main effect of condition [all $F(1,36)>4.1 ; p<.01 ; \eta^{2}>.10$ ], no effect of group (all $F<1$ ), and a significant interaction between condition $\times$ group [all $F(1,36)>2.8 ; p<.05 ; \eta^{2}>.07$ ] for all the significant time windows (i.e., priming effects) in LIFG pars triangularis, LIFG pars orbitalis and left orbitofrontal gyrus (for a detailed presentation of these analyses see Table S4 in the Supplementary Materials).

For dyslexics, results in the LIFG pars triangularis (red box) revealed a significant global morphological priming effect

\footnotetext{
${ }^{1}$ Significant time windows were found using a method proposed by Maris and Oostenveld (2007). This method consists of applying a paired t-tests on each time point between two experimental conditions and the resulting t-values were corrected for multiple comparison over the time period of 0-650 msec using a cluster-based permutation t-test (i.e., 10,000 random permutations). In addition, we further corrected the significant $p$-values using the FDR correction (Benjamini \& Hochberg, 1995).
}

( $p=.02$ less than the $\mathrm{BH}$ threshold $q=.03$ for the cluster at 115-195 msec, Fig. 3A). The M+S+ effect was significant between 150 and $205 \mathrm{msec}(p=.04$, less than the BH threshold $q=.05$, Fig. 3B) and also between 380 and $435 \mathrm{msec}(p=.02$, less than the $\mathrm{BH}$ threshold $q=.04$, Fig. 3B). The $\mathrm{M}+\mathrm{O}+$ effect was significant between 210 and $270 \mathrm{msec}(p=.01$, less than the $\mathrm{BH}$ threshold $q=.02$, Fig. $3 \mathrm{C}$ ). No significant effects were obtained for pure orthographic (Fig. 3D) and pure semantic priming (Fig. 3E).

For skilled readers, results in the LIFG pars orbitalis (green box) revealed a significant global morphological priming effect ( $p=.007$ less than the $\mathrm{BH}$ threshold $q=.01$ for the cluster at 350-460 msec, Fig. 3A). The $\mathrm{M}+\mathrm{S}+$ effect was significant between 440 and $495 \mathrm{msec}(p=.04$, less than the BH threshold $q=.05$, Fig. $3 \mathrm{~B}$ ) and the $\mathrm{M}+\mathrm{O}+$ effect was significant between 345 and $420 \mathrm{msec}(p=.01$, less than the BH threshold $q=.02$, Fig. 3C). No significant effects were obtained for pure orthographic (Fig. 3D) and pure semantic priming (Fig. 3E). None of the other contrasts revealed significant effects in any of the windows.

In the left orbitofrontal gyrus (blue box), no global morphological priming effect was found for dyslexics. However, results revealed a significant $\mathrm{M}+\mathrm{S}+$ effect in an early 
time window $(p=.005$ less than the $\mathrm{BH}$ threshold $q=.008$ for the cluster at $45-170 \mathrm{msec}$, Fig. 3B). None of the other contrasts revealed significant effects in that region. For skilled readers, results in the left orbitofrontal gyrus (blue box) revealed a significant global morphological priming effect in the M350 (magnetic N400) time window ( $p=.0006$ less than the $\mathrm{BH}$ threshold $q=.002$ for the cluster at 320-465 msec Fig. 3A) and a significant $\mathrm{M}+\mathrm{S}+$ effect in a somewhat smaller and later time window ( $p=.01$ less than the $\mathrm{BH}$ threshold $q=.03$ for the cluster at $435-500 \mathrm{msec}$, Fig. 3B).

\subsubsection{Left occipito-temporal regions}

Fig. 4 displays the time course of average activation within the left occipito-temporal regions, both for dyslexic and skilled readers. The results showed a dissociated pattern of activation on both spatial and temporal dimensions where significant effects were only found in the left middle FG for dyslexics and only in the posterior LITG for skilled readers. A condition $\times$ group mixed design ANOVA yielded a main effect of condition [all $F(1,36)>2.9 ; p<.05 ; \eta^{2}>.08$ ], no effect of group (all $F<1$ ), and a significant interaction between condition $\times$ group [all $F(1,36)>2.7 ; p<.05 ; \eta^{2}>.08$ ] for all the significant time windows (i.e., priming effects) in left middle FG and posterior LITG.

For the dyslexics, results in the left middle FG (blue box) revealed a significant global morphological priming effect in two time-windows $(p=.009$ less than the BH threshold $q=.01$ for the cluster at 205-310 msec; $p=.008$ less than the $\mathrm{BH}$ threshold $q=.02$ for the cluster at 385-500 msec, Fig. 4A) and a significant $\mathrm{M}+\mathrm{O}+$ effect $(p=.01$ less than the $\mathrm{BH}$ threshold $q=.03$ for the cluster at 200-245 msec, Fig. 4C). Moreover, there was a significant effect of pure orthographic priming in the later time window between 445 and $520 \mathrm{msec}(p=.02$, less than the $\mathrm{BH}$ threshold $q=.04$, Fig. $4 \mathrm{D}$ ) and a pure semantic priming effect between 440 and $535 \mathrm{msec}(p=.001$, less than the BH threshold $q=.005$, Fig. $4 \mathrm{E}$ ).

For the skilled readers, results in the posterior LITG (red box) revealed significant differences only for the pure orthographic priming effect $(p=.02$ less than the $\mathrm{BH}$ threshold $q=.04$ for the cluster at 55-120 msec, Fig. 4D). None of the other contrasts revealed significant time windows in posterior LITG (see also Fig. S5).

Figs. S4 and S5 (Supplementary Materials) display the time course of average activation within the anterior part of the left FG, and within the posterior and middle part of the LITG, respectively, both for dyslexic and skilled readers. For the anterior part of the left FG, results for the dyslexics showed a significant global morphological priming effect between 80 and $205 \mathrm{msec}$ and a pure orthographic priming effect between 80 and $140 \mathrm{msec}$. None of the other contrasts revealed significant effects in that region, and no effect was found for any of the contrast for the skilled readers in that region (Fig. S4). For the middle part of the LITG, results for the dyslexics showed a significant global morphological priming effect in two time windows (220-310 msec and 370-525 msec). Moreover, there was a significant pure semantic priming effect between 420 and $525 \mathrm{msec}$. For the skilled readers, results showed significant global morphological priming effect between 325 and $450 \mathrm{msec}$ and both the $\mathrm{M}+\mathrm{O}+$ and $\mathrm{M}+\mathrm{S}+$ effects were significant in the time window of the M350 (Fig. S5).

\subsubsection{LSTG}

Fig. 5 displays the time course of average activation within the LSTG, both for dyslexic and skilled readers. A condition $\times$ group mixed design ANOVA yielded a main effect of condition [all $F(1,36)>4.0 ; p<.05 ; \eta^{2}>.10$ ], no effect of group (all $F<1$ ), and a significant interaction between condition $\times$ group [all $F(1,36)>3.8 ; p<.05 ; \eta^{2}>.08$ ] (footnote ${ }^{2}$ ) for all the significant time windows (i.e., priming effects) in LSTG.

For the dyslexics, results in the LSTG (right column) revealed a significant effect of pure orthographic priming between 425 and 490 msec ( $p=.01$, less than the BH threshold $q=.03$ Fig. 5D) and a pure semantic priming effect between 435 and $520 \mathrm{msec}(p=.008$, less than the BH threshold $q=.01$ Fig. 5E). The timing of these effects is consistent with the time window of the late M350. None of the other contrasts revealed significant effects in that region.

For the skilled readers, results in the LSTG (left column) revealed no significant global morphological priming effect (Fig. 5A). However, we found a significant difference for the $\mathrm{M}+\mathrm{S}+$ effect in the time window of the M250 $(p=.02$ less than the BH threshold $q=.04$ for the cluster at $240-300 \mathrm{msec}$, Fig. $5 B$ ), and in a later time window that started at $\sim 580 \mathrm{msec}$ after target onset $(p=.04$ less than the $\mathrm{BH}$ threshold $q=.05$ for the cluster at 585-650 $\mathrm{msec}$ ). None of the other contrasts revealed significant effects in that region. However, as concerns the pure semantic priming effect, a condition (semantic us unrelated) $\times$ group (dyslexic us control) ANOVA yielded a main effect of condition $\left[F(1,36)=14.9 ; p<.001 ; \eta^{2}=.29\right]$, no effect of group (all $F<1)$, and no interaction between condition $\times$ group $[F(1,36)=2.2 ; p=.12]$ suggesting that the pure semantic effect found in the late M350 time window for the dyslexics is also present (but not significant) for the skilled readers group.

\subsection{Correlation analysis}

To investigate whether the size of the morphological priming effects in the different ROIs was related to the severity of the reading impairment (i.e., more severely impaired readers might show stronger reliance on morphological information), we conducted correlation analyses between the size of the morphological priming effects in the significant time windows of the different ROIs and the overall reading level of the dyslexic participants, as indexed by the standardized reading test. Holm-Bonferroni correction for multiple comparisons was used to set significance thresholds (Holm, 1979). Only two significant correlations were found, in the LIFG pars triangularis in the [115-195] msec time window (Fig. 6 left) and in the left middle FG in the [385-500] msec time window (Fig. 6 right). As shown in Fig. 6, the more severely impaired dyslexics showed greater early morphological processing in LIFG $(r=-.51 ; p<.02)$ and greater late morphological processing in left middle FG $(r=-.50 ; p<.05)$ than the less severely impaired dyslexics.

To investigate whether early morphological processing in left inferior frontal regions would influence late lexico-

\footnotetext{
2 Only for the pure semantic priming effect there was no significant interaction between condition and group $[F(1,36)=2.2$; $p=.12]$.
} 
Post part of left ITG

SR
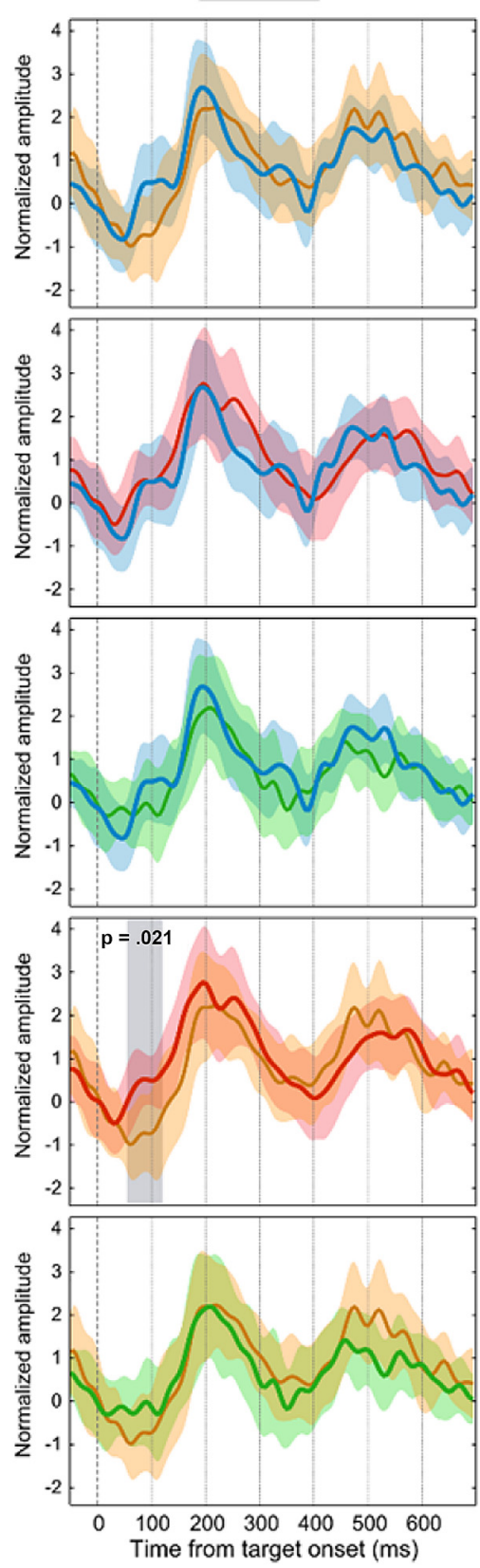

Ventral

Middle part of left FG

DYS
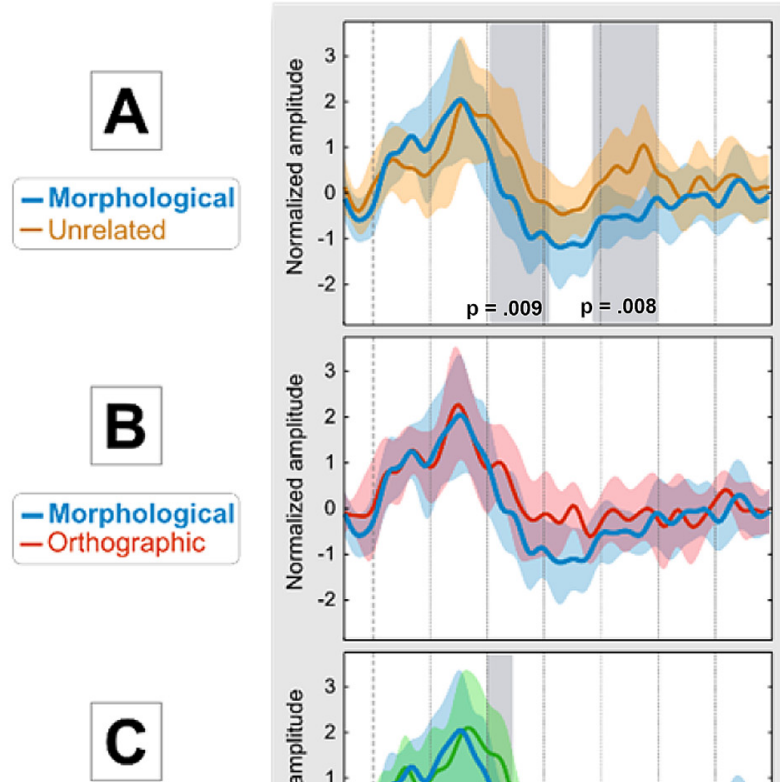

-Morphological - Semantic

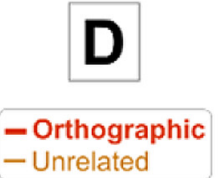

- Unrelated
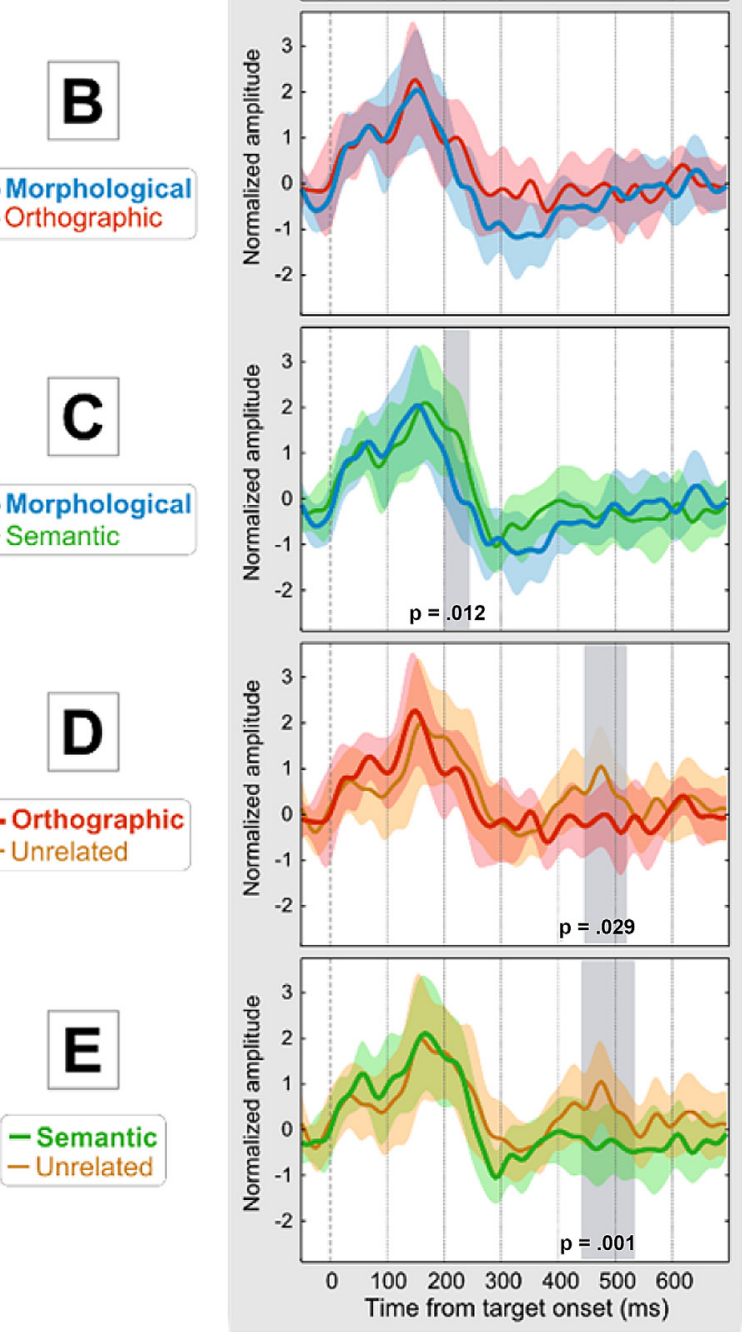

Fig. 4 - Location of the left occipito-temporal ROIs. Red box (left) corresponds to the posterior left inferior temporal gyrus (ITG; 7 dipoles), Blue box (right) corresponds to the middle left fusiform gyrus (FG; 7 dipoles). (A) Global morphological priming effect, $\mathbf{M}+$, and 95\% Confidence Interval (see Allen et al., 2012) for dyslexic readers (DYS) and for skilled readers (SR), (B) $\mathbf{M}+\mathbf{S}+$ effect, (C) $\mathbf{M}+\mathbf{O}+$ effect, (D) pure orthographic priming effect, $\mathbf{O}+$, and (E) pure semantic priming effect, $\mathbf{S}+$. The significant time windows are presented in vertical gray band with the corresponding $p$ value after correction for multiple comparisons (nonparametric permutation test). 

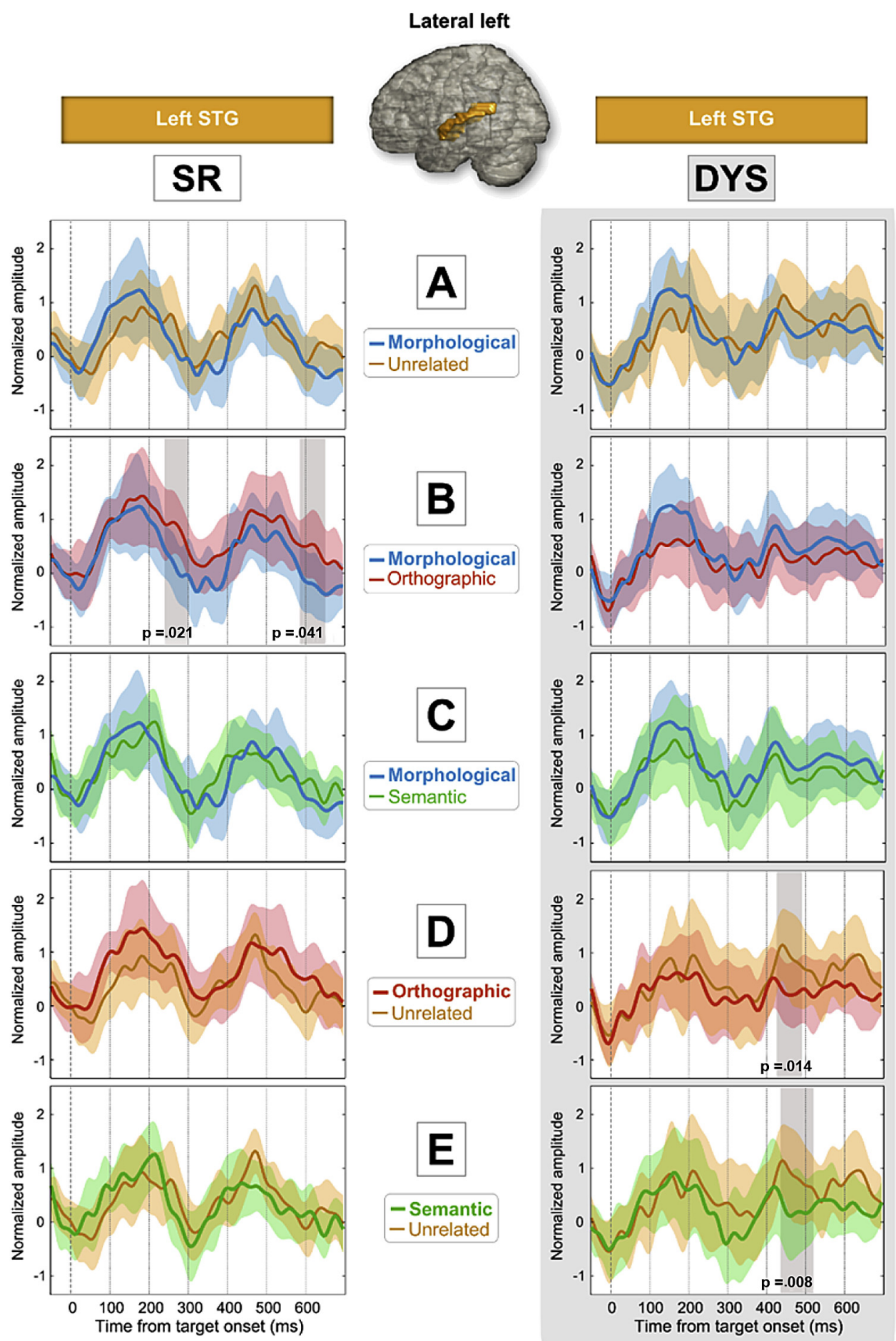

Fig. 5 - Location of the left superior temporal ROI (LSTG; 22 dipoles). Red box (left) corresponds to the skilled readers group (SR), Blue box (right) corresponds to the dyslexic readers group (DYS). (A) Global morphological priming effect, M+, and 95\% Confidence Interval (see Allen et al., 2012) for dyslexic readers and for skilled readers, (B) $\mathbf{M}+\mathbf{S}+$ effect, (C) $\mathbf{M}+\mathbf{O}+\mathbf{e f f e c t}$, (D) pure orthographic priming effect, $\mathrm{O}_{+}$, and $(\mathrm{E})$ pure semantic priming effect, $\mathrm{S}+$. The significant time windows are presented in vertical gray band with the corresponding $p$ value after correction for multiple comparisons (nonparametric permutation test).

semantic processing in left occipito-temporal regions in dyslexic individuals, we computed correlation analyses (Holm-Bonferroni correction) between activity related to the $\mathrm{M}+$ effect in LIFG during the [115-195] msec time window and in the left middle FG during the [205-310] and the [385-500] msec time windows. Results showed a significant correlation between activity in LIFG and left middle FG in the [115-195] and [205-310] msec time windows, respectively $(r=.47$; 

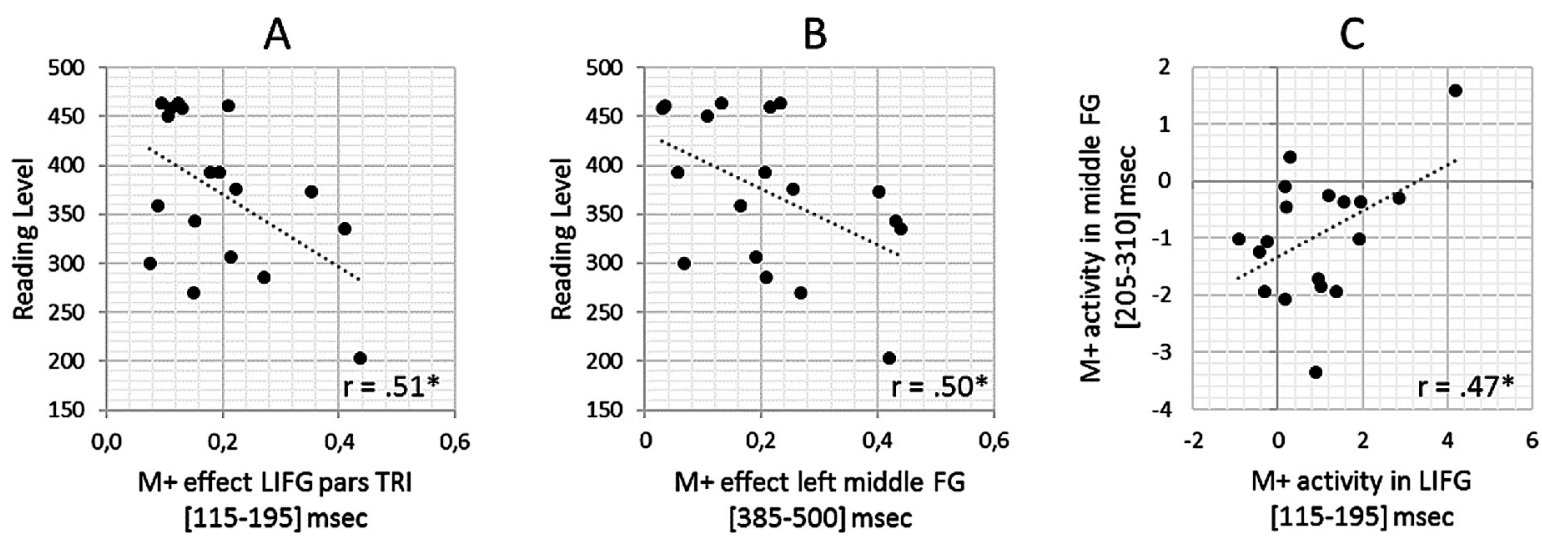

Fig. 6 - Correlation and regression line between reading level (CTL efficiency score at the Alouette reading test) obtained by dyslexic readers and the size of morphological priming effect (i.e., the mean difference of the absolute activity values between both morphological and unrelated conditions for each dyslexic participant) in LIFG pars triangularis during the significant 115-195 msec time window (Fig. 6A) and in the left middle FG during the significant 385-500 msec time window (Fig. 6B). Fig. 6C shows correlation between activity related to the M+effects in LIFG during the [115-195] msec time window and in the left middle FG during the [205-310] msec time window.

$p=.02)$, but a non-significant correlation between LIFG and left middle FG in a later time window [385-500] msec $(r=.12$; $p=.62$ ). The correlation between activity in the left middle FG [205-310] and left middle FG [385-500] msec time windows was significant $(r=.45 ; p=.03)$. Although these results cannot be considered as index of functional connectivity, they seem to suggest a potential top-down mechanism in dyslexia through which morphological processing in frontal regions might influence lexico-semantic processing in occipitotemporal regions.

\section{Discussion}

The main aim of this study was to investigate the differences between high achieving adult dyslexics and skilled readers in the processing of morphological, orthographic and semantic information in a primed-lexical decision task. We hypothesized that high-achieving adult dyslexics use information related to the morphological structure of words differently from non-impaired skilled readers. At the behavioral level, the results are consistent with this hypothesis. First, we found that adults with dyslexia exhibit greater morphological priming effects than controls. In addition, the interaction between the $\mathrm{M}+\mathrm{S}+$ effect and Group suggests that adult dyslexics might rely more strongly on the semantic rather than the orthographic properties of the morphemes.

At the brain level, we hypothesized to find spatiotemporal differences between high-achieving adult dyslexics and skilled readers in processing morphological information with possibly earlier and stronger activation of morphology in adult dyslexics in more frontal parts of the brain. Sensor-based analyses suggested that differences were mainly localized in the anterior and posterior left sites, and group differences were only found for the early M170 and late M350 time windows. Source-space analyses, however, revealed a spatiotemporal reorganization of the reading network for dyslexics, in which morphological information in frontal regions was activated more strongly and earlier in dyslexics than controls, which was taken to suggest that morphological processing plays a special role as a compensatory mechanism in highachieving adult dyslexics. The evidence in favor of this hypothesis is discussed below.

\subsection{Early activation in the left inferior frontal regions}

The major finding of the present study was that highachieving adult dyslexics showed morphological priming effects in left inferior frontal regions in the first $200 \mathrm{msec}$, whereas these regions showed priming effects in skilled readers only at $\sim 400 \mathrm{msec}$. More specifically, in the left orbitofrontal gyrus, dyslexics showed a significant $\mathrm{M}+\mathrm{S}+$ priming effect between 45 and $170 \mathrm{msec}$. In contrast, skilled readers showed a $\mathrm{M}+\mathrm{S}+$ priming effect in this ROI only in a late M350 time window (435-500 $\mathrm{msec})$. Interestingly, previous MEG studies in normal readers showed that left orbitofrontal gyrus is involved in semantic composition and semantic coherence (i.e., the gradient semantic fit of stems and affixes) during the 350-500 msec time window (Fruchter \& Marantz, 2015). The fact that our morphological priming effect in this region seemed to be semantic in nature $(\mathrm{M}+\mathrm{S}+$ effect) is consistent with their finding. As shown by Bar et al. (2006) using MEG, rapid activation of the left orbitofrontal gyrus represents facilitates object recognition via feedback to the left inferior temporal and fusiform gyri. In line with this finding, it could be suggested that the early activation of the left orbitofrontal gyrus in adults with dyslexia may reflect the activation of morpho-semantic information that is used in a top-down fashion to improve lexico-semantic processing in left inferior temporal and fusiform gyri. This interpretation is supported by a significant correlation between early activity in LIFG and subsequent activity in left middle FG.

An interesting spatio-temporal dissociation between dyslexics and controls was obtained in LIFG. Dyslexic readers exhibited significant morphological activation only in the pars triangularis of the LIFG, in which the $\mathrm{M}+\mathrm{S}+$ effect 
(150-205 msec) occurred before the $\mathrm{M}+\mathrm{O}+$ effect (210-270 msec). In contrast, skilled readers exhibited significant activation only in the pars orbitalis of the LIFG, in which the $\mathrm{M}+\mathrm{O}+$ effect (345-420 $\mathrm{msec}$ ) occurred before the $\mathrm{M}+\mathrm{S}+$ effect (440-490 msec). Thus, specific morphological activation does not only occur earlier in dyslexics than controls ( 200 us $\sim 400 \mathrm{msec}$ ), but the specific nature of the morphological priming effect seems to differ. High-achieving adult dyslexics seem to process the semantic properties of morphological primes before their orthographic properties, while the opposite is true for controls. Crucially, for both groups, the morphology-specific effects could not be explained by pure orthographic or semantic overlap because the pure effects yielded no significant differences in the LIFG pars triangularis or orbitalis.

Previous imaging research has suggested that the pars triangularis (BA45) is involved in semantic decisions (Gough, Nobre, \& Devlin, 2005; Goucha \& Friederici, 2015; Hagoort, 2005; Price, 2012) and phonological processing (Price, 2012; Shaywitz et al., 1998) but also in processing inflectional morphology (syntactic markers), with distinct sequential activation peaks that corresponded to lexical ( $200 \mathrm{msec})$, syntactic/inflectional ( 320 $\mathrm{msec})$ and phonological ( 400 msec) processing (Sahin, Pinker, Cash, Schomer, \& Halgren, 2009). The pars orbitalis (BA47) is involved in semantic encoding and the active selection or retrieval of semantic concepts (Binder, Desai, Graves, \& Conant, 2009; Price, 2012; Saur et al., 2008) but also in processing morphology and morpho-syntactic information (see Koester \& Schiller, 2011). Our finding that $\mathrm{M}+\mathrm{O}+$ information in skilled readers is processed slightly earlier than $\mathrm{M}+\mathrm{S}+$ information in pars orbitalis is consistent with a feedforward morphological decomposition process (see Whiting et al., 2015), and goes well with the hypothesis that morphological form information is processed before meaning (see Rastle \& Davis, 2008). In contrast, in highachieving adult dyslexics, $\mathrm{M}+\mathrm{S}+$ effects occur before $\mathrm{M}+\mathrm{O}+$ effects in pars triangularis, which suggests that semantic information is used to constrain morphological processing in this population (Diependaele, Dunabeitia, Morris, \& Keuleers, 2011; Feldman, O'Connor, \& Moscoso de Prado Martin, 2009; Feldman, Milin, Cho, Moscoso del Prado Martin, \& O'Connor, 2015).

How could we further explain these early effects of morphological facilitation in frontal regions? As suggested by Elbro and Arnbak (1996), dyslexics might use a reading strategy based on morphemes rather than graphemes and phonemes. We suggest that adult dyslexics decompose the prime very quickly into morphological units and start to compute the meaning of these morphemes (i.e., morpho-semantic processing). This is in line with Quémart and Casalis (2013) who found that morphological priming in children with dyslexia is mainly due to morpho-semantic processing. Therefore, upon presentation of the target $(250 \mathrm{msec}$ after the presentation of the prime), in the morphologically related condition, the morphological units of the target are already pre-activated by the prime and their meanings have, at least partially, been processed, which leads to a strong behavioral and neural priming effect (i.e., faster RTs and early morphological priming in frontal regions). Presumably, skilled adult readers might do a quick morpho-orthographic analysis of the prime but do not analyze the meanings of the morphemes any further. This is consistent with the finding that early morphoorthographic segmentation is semantically "blind" (Beyersmann et al., 2016; Rastle \& Davis, 2008). As a consequence, skilled adult readers do not show the early semantically driven morphological priming effects in frontal regions but only the classic morphological priming effects that occur around $350 \mathrm{msec}$ in frontal regions (M350).

As stated in the introduction, previous fMRI studies have reported over-activation of the left frontal regions in adults with dyslexia, which has often been interpreted in terms of increased effort in activating phonological codes or articulatory compensation (see reviews by Pugh et al., 2000; Richlan et al., 2011; Shaywitz \& Shaywitz, 2005). Our results suggest that the (over)-activation of the frontal areas (left BA45 and orbitofrontal regions) could also reflect the greater reliance on morphological processes in adults with dyslexia compared to controls. Hypothetically, the stronger reliance on morphological processes could be seen as one of the neural signatures for compensation. Indeed, our correlation analyses suggest that the greater the reading impairment of dyslexics, the more they rely on morphological processing in this region (i.e., the greater the morphological priming effect). This view is different from the idea that over-activation of the pars triangularis in adults with dyslexia might exclusively be due to covert articulation or increased effort.

\subsection{Late activation in the left temporal and occipito- temporal regions}

The second main finding of the present study is that dyslexics exhibited prelexical and lexico-semantic priming effects in the left posterior occipito-temporal gyrus from 100 to $500 \mathrm{msec}$, whereas skilled readers showed only prelexical orthographic priming effect in this region at $\sim 100 \mathrm{msec}$. In particular, skilled readers showed a pure orthographic priming effect in posterior LITG at 100 msec, whereas dyslexics readers showed morphological priming effect in left anterior FG around 100-200 msec (see Fig. S4, Supplementary Materials) and lexico-semantic priming effect in left middle FG during the 205-500 msec time window.

The orthographic priming effect in skilled readers seems to correspond to an early M130 response associated with prelexical orthographic processing (Cohen et al., 2000; Dehaene, Le Clec, Poline, Le Bihan, \& Cohen, 2002; Vinckier et al., 2007; Zhao et al., 2016). The absence of an orthographic priming effect in this region in dyslexics is consistent with many neuroimaging studies that consistently showed dysfunctional activation of the left occipito-temporal cortex in adults and children with dyslexia (Boros et al., 2016; Helenius et al., 1999; Kronbichler et al., 2006; Richlan et al., 2011). In contrast, prelexical morphological and orthographic processing seem to occur in the anterior part of the left FG in high achieving adult dyslexics during the 100-205 $\mathrm{msec}$ time window. Moreover, dyslexics showed significant priming in the middle part of the left FG with a global morphological priming effect in the 205-310 msec time window. Crucially, the global morphological effect "survived" only when semantic overlap was controlled for $(\mathrm{M}+\mathrm{O}+$ effect) suggesting that the effect taps the orthographic contribution to morphological facilitation in 
the 200-245 msec time window. Given the hierarchical organization of visual processing along the ventral route (posterior-to-anterior gradient reflecting more integrated word processing in anterior parts of the ventral stream in unimpaired readers; see Vinckier et al., 2007), results of dyslexics suggest a spatiotemporal reorganization of the ventral stream. Indeed, it seems that prelexical orthographic and morphological processing occur in the anterior part of the left FG, while more integrated morpho-orthographic processing occurs in the middle part. Thus, the left FG in adults with dyslexia seems to be sensitive to morpho-orthographic representations, suggesting that high-achieving adult dyslexics might have developed a reading strategy based on morphemesized orthographic units rather than smaller units, such as graphemes (Elbro \& Arnbak, 1996).

Furthermore, in line with the hypothesis that the left FG exhibits an altered anterior-to-posterior gradient in high achieving adult dyslexics, results also showed a later global morphological priming effect in the left middle FG in the 385-500 msec time window and pure effects of orthographic and semantic priming around 445-520 msec and 440-535 msec, respectively. Thus, in this late time window, the global effects of morphology can be fully explained by overlap in form and meaning, which is consistent with previous fMRI studies (Devlin, Jamison, Matthews, \& Gonnerman, 2004). Such late activation of semantic and orthographic information might reflect top-down influences from left inferior frontal regions to ventral occipito-temporal cortex (see Carreiras, Armstrong, Perea, \& Frost, 2014), as suggested by a significant positive correlation between activity related to morphological processing in LIFG and left middle FG (see Fig. 6). This hypothesis is in line with the predictive coding framework (Price \& Devlin, 2011) and supported by studies showing that feedback from the inferior frontal cortex plays a role in facilitating visual word processing in unimpaired readers (Cornelissen et al., 2009; Price \& Devlin, 2011; Woodhead et al., 2014) and also in patients with pure alexia (Woodhead et al., 2013). A recent tractography study in adults with dyslexia showed that the left inferior fronto-occipital fasciculus which sustains the direct orthographic reading route presents no difference in fractional anisotropy compared to the control group (Vandermosten et al., 2012), which supports the idea that the direct route between the LIFG and the left FG may be efficient in adults with dyslexia and can be used to compensate for their orthographic processing difficulties (Hoeft et al., 2011). Results in the LITG (see Fig. S5, Supplementary Materials) are in favor of this hypothesis. Indeed, while for skilled readers the middle and anterior parts of LITG are involved in orthographic and semantic access of morphemes, as revealed by the M350 (see Brooks \& Cid de Garcia, 2015; Cavalli et al., 2016), results for dyslexics revealed significant morphological and semantic priming effects in the $400-520$ msec time window, suggesting a specific role of the left fronto-temporal route in lexico-semantic processing (see also Fonteneau, Bozic, \& Marslen-Wilson, 2015, for evidence of left fronto-temporal cross-cortical interactions of morphosyntax in speech recognition).

Finally, the results of the present study suggest that the LSTG, a region that has shown to be involved in lexical access and early morphological decomposition in skilled adult readers (e.g., Jobard et al., 2003; Price, 2012; Whiting et al., 2015), showed significant effects of pure orthographic and semantic priming around $425-520 \mathrm{msec}$ in dyslexics, but no global morphological or morphology-specific effects. In contrast, skilled readers showed a significant $\mathrm{M}+\mathrm{S}+$ effect in the time window of the M250, suggesting that the LSTG is associated with morpho-semantic decomposition in skilled readers but not in dyslexics (Fruchter \& Marantz, 2015). The late effects of pure orthographic and semantic priming in dyslexic readers are consistent with numerous findings showing that one of the persistent features of dyslexia is slow lexical access for written words (e.g., Helenius et al., 1999).

\section{Conclusion}

This study is the first to show an earlier and stronger contribution of morphological processes in high-achieving adult dyslexics compared to normal readers. In line with the interactive compensatory hypothesis (Stanovich, 1980), our results suggest that early morphological processing in adult dyslexics takes place in the LIFG within the first $200 \mathrm{msec}$ and relies primarily on the semantic properties of morphemes. The early effects of morphology in LIFG might provide feedback to facilitate morpho-orthographic processing in the left occipitotemporal cortex. Together, the findings suggest (1) a greater reliance on morphological and morpho-semantic processing in adults with dyslexia and (2) a spatiotemporal reorganization of the reading network in which frontal parts of the brain seem to be engaged earlier in morpho-semantic processing in adult dyslexics than controls. Further studies are needed to investigate the functional connectivity between the left inferior frontal and left occipito-temporal networks in highachieving adult dyslexics to directly test the interactive compensatory hypothesis in the context of the predictive coding framework.

\section{Conflict of interest}

The authors declare that the research was conducted in the absence of any commercial or financial relationships that could be construed as a potential conflict of interest.

\section{Acknowledgements}

This work was supported by French Life Imaging (FLI) and the Labex BLRI (ANR-11-LABX-0036), managed by the French National Agency for Research (ANR), under the project title Investments of the Future A*MIDEX (ANR-11-IDEX-0001- 02). Eddy Cavalli was supported by a grant from the French Ministry of Research (2013-2016). We are grateful to all students who volunteered to participate in the study. Special thanks are extended to Florence Poracchia-George and Catherine Pech-Georgel (IDEC/CERTA, Hôpital Salvator, Marseille) for their help with the recruitment and diagnosis of the students with dyslexia. We thank two anonymous reviewers for their excellent comments and suggestions. 


\section{Supplementary data}

Supplementary data related to this article can be found at http://dx.doi.org/10.1016/j.cortex.2017.04.012.

\section{R E F E R E N C ES}

Allen, E. A., Erhardt, E. B., \& Calhoun, V. D. (2012). Data visualization in the neurosciences: Overcoming the curse of dimensionality. Neuron, 74, 603-608.

Bar, M., Kassam, K. S., Ghuman, A. S., Boshan, J., Schmidt, A. M., Dale, A. M., et al. (2006). Top-down facilitation of visual recognition. Proceedings of the National Academy of Sciences of the United States of America, 103, 449-454.

Benjamini, Y., \& Hochberg, Y. (1995). Controlling the false discovery rate: A practical and powerful approach to multiple testing. Journal of the Royal Statistical Society, Series B, 57, 289-300.

Bertrand, D., Fluss, J., Billard, C., \& Ziegler, J. C. (2010). Efficacité, sensibilité, spécificité : Comparaison de différents tests de lecture [Efficiency, sensitivity, specificity: Comparison of different reading tests]. L'Année Psychologique, 110, 299-320.

Beyersmann, E., Iakimova, G., Ziegler, J. C., \& Colé, P. (2014). Semantic processing during morphological priming: An ERP study. Brain Research, 1579, 45-55.

Beyersmann, E., Ziegler, J. C., Castles, A., Coltheart, M., Kezilas, Y., \& Grainger, J. (2016). Morpho-orthographic segmentation without semantics. Psychonomic Bulletin \& Review, 23, 533-539.

Binder, J. R., Desai, R. H., Graves, W. W., \& Conant, L. L. (2009). Where is the semantic system? A critical review and metaanalysis of 120 functional neuroimaging studies. Cerebral Cortex, 19, 2767-2796.

Boets, B., Op de Beeck, H. P., Vandermosten, M., Scott, S. K., Gillebert, C. R., Mantini, D., et al. (2013). Intact but less accessible phonetic representation in adults with dyslexia. Science, 342, 1251-1254.

Boros, M., Anton, J.-L., Pech-Georgel, C., Grainger, J., Szwed, M., \& Ziegler, J. C. (2016). Orthographic processing deficits in developmental dyslexia: Beyond the ventral visual stream. NeuroImage, 128, 316-327.

Bozic, M., Marslen-Wilson, W. D., Stamatakis, E. A., Davis, M. H., \& Tyler, L. K. (2007). Differentiating morphology, form, and meaning: Neural correlates of morphological complexity. Journal of Cognitive Neuroscience, 19, 1464-1475.

Brooks, T. L., \& Cid de Garcia, D. (2015). Evidence for morphological composition in compound words using MEG. Frontiers in Human Neuroscience, 9, 215.

Brunswick, N., McCrory, E., Price, C. J., Frith, C. D., \& Frith, U. (1999). Explicit and implicit processing of words and pseudowords by adult developmental dyslexics: A search for Wernicke's Wortschatz? Brain, 122, 1901-1917.

Carreiras, M., Armstrong, B. C., Perea, M., \& Frost, R. (2014). The what, when, where and how of visual word recognition. Trends in Cognitive Sciences, 18, 90-98.

Cavalli, E., Casalis, S., El Ahmadi, A., Zira, M., Poracchia-G, F., \& Colé, P. (2016a). Vocabulary skills are well developed in university students with dyslexia: Evidence from multiple case studies. Research in Developmental Disabilities, 51-52, 89-102.

Cavalli, E., Colé, P., Badier, J. M., Zielinski, C., Chanoine, V., \& Ziegler, J. C. (2016b). Spatio-temporal dynamics of morphological processing in visual word recognition. Journal of Cognitive Neuroscience, 28, 1228-1242.

Cavalli, E., Colé, P., Leloup, G., Poracchia-George, F., SprengerCharolles, L., \& El Ahmadi, A. (2017). Screening for Dyslexia in
French-Speaking University Students: An Evaluation of the Detection Accuracy of the Alouette Test. Journal of Learning Disabilities. Advance on. http://doi.org/10.1177/ 0022219417704637.

Cavalli, E., Duncan, L. G., Elbro, C., El Ahmadi, A., \& Colé, P. (2017). Phonemic-morphemic dissociation in university students with dyslexia: An index of reading compensation? Annals of Dyslexia, 67, 63-84.

Cohen, L., Dehaene, S., Naccache, L., Lehericy, S., DehaeneLambertz, G., Henaff, M. A., et al. (2000). The visual word form area - spatial and temporal characterization of an initial stage of reading in normal subjects and posterior split-brain patients. Brain, 123, 291-307.

Colombet, B., Woodman, M., Bénar, C. G., \& Badier, J. M. (2015). AnyWave: A cross-platform and modular software for visualizing and processing electrophysiological signals. Journal of Neuroscience Methods, 242, 118-126.

Cornelissen, P. L., Kringelbach, M. L., Ellis, A. W., Whitney, C., Holliday, I. E., \& Hansen, P. C. (2009). Activation of the left inferior frontal gyrus in the first $200 \mathrm{~ms}$ of reading: Evidence from magnetoencephalography (MEG). PLoS One, 4, e5359.

Deacon, S. H., Cook, K., \& Parrila, R. (2012). Identifying highfunctioning dyslexics: Is self-report of early reading problems enough? Annals of Dyslexia, 62, 120-134.

Dehaene, S., Le Clec, H. G., Poline, J. B., Le Bihan, D., \& Cohen, L. (2002). The visual word- form area: A prelexical representation of visual words in the fusiform gyrus. NeuroReport, 13, 321-325.

Demonet, J. F., Taylor, M. J., \& Chaix, Y. (2004). Developmental dyslexia. Lancet, 363, 1451-1460.

Devlin, J. T., Jamison, H. L., Matthews, P. M., \& Gonnerman, L. M. (2004). Morphology and the internal structure of words. Proceedings of the National Academy of Sciences of the United States of America, 101, 14984-14988.

Diependaele, K., Dunabeitia, J. A., Morris, J., \& Keuleers, E. (2011). Fast morphological effects in first and second language acquisition. Journal of Memory and Language, 64, 344-358.

Dunn, L. M., Thériault-Whalen, C. M., \& Dunn, L. M. (1993). Echelles de vocabulaire en image Peabody. Adaptation française du Peabody Picture Vocabulary Test-Revised. Toronto: Psycan.

Elbro, C., \& Arnbak, A. (1996). The role of morpheme recognition and morphological awareness in dyslexia. Annals of Dyslexia, 46, 209-240.

Feldman, L. B., Milin, P., Cho, K. W., Moscoso del Prado Martín, F., \& O'Connor, P. A. (2015). Must analysis of meaning follow analysis of form? A time course analysis. Frontiers in Human Neuroscience, 9, 1-19.

Feldman, L. B., O'Connor, P. A., \& Moscoso del Prado Martin, F. (2009). Early morphological processing is morpho-semantic and not simply morpho-orthographic: A violation of formthen-meaning accounts of word recognition. Psychonomic Bulletin \& Review, 16, 684-691.

Fonteneau, E., Bozic, M., \& Marslen-Wilson, W. D. (2015). Brain network connectivity during language Comprehension: Interacting linguistic and perceptual subsystems. Cerebral Cortex, 25, 3962-3976.

Friederici, A. D. (2011). The brain basis of language processing: From structure to function. Physiological Reviews, 91, 1357-1392.

Fruchter, J., \& Marantz, A. (2015). Decomposition, lookup, and recombination: MEG evidence for the full decomposition model of complex visual word recognition. Brain and Language, 143, 81-96.

Gabrieli, J. D. E. (2009). Dyslexia: A new synergy between education and cognitive neuroscience. Science, 17, 280-283.

Goucha, T., \& Friederici, A. D. (2015). The language skeleton after dissecting meaning: A functional segregation within Broca's area. NeuroImage, 114, 294-302. 
Gough, P. M., Nobre, A. C., \& Devlin, J. T. (2005). Dissociating linguistic processes in the left inferior frontal cortex with transcranial magnetic stimulation. The Journal of Neuroscience, 25, 8010-8016.

Haft, S. L., Myers, C. A., \& Hoeft, F. (2016). Socio-emotional and cognitive resilience in children with reading disabilities. Current Opinion in Behavioral Sciences, 10, 133-141.

Hagoort, P. (2005). On Broca, brain, and binding: A new framework. Trends in Cognitive Sciences, 9, 416-423.

Harpaz, Y., Lavidor, M., \& Goldstein, A. (2013). Right semantic modulation of early MEG components during ambiguity resolution. NeuroImage, 82, 107-114.

Helenius, P., Salmelin, R., Service, E., \& Connolly, J. F. (1999). Semantic cortical activation in dyslexic readers. Journal of Cognitive Neuroscience, 11, 535-550.

Hoeft, F., McCandliss, B. D., Black, J. M., Gantman, A., Zakerani, N., Hulme, C., et al. (2011). Neural systems predicting long-term outcome in dyslexia. Proceedings of the National Academy of Sciences of the United States of America, 108, 361-366.

Holm, S. (1979). "A simple sequentially rejective multiple test procedure". Scandinavian Journal of Statistics, 6, 65-70.

Holme, C. J., Hoge, R., Collins, L., Woods, R., Toga, A. W., \& Evans, A. C. (1998). Enhancement of MR images using registration for signal averaging. Journal of Computer Assisted Tomography, 22, 324-333.

Jobard, G., Crivello, F., \& Tzourio-Mazoyer, N. (2003). Evaluation of the dual route theory of reading: A metanalysis of 35 neuroimaging studies. NeuroImage, 20, 693-712.

Koester, D., \& Schiller, N. O. (2011). The functional neuroanatomy of morphology in language production. NeuroImage, 55, 732-741.

Kronbichler, M., Hutzler, F., Staffen, W., Mair, A., Ladurner, G., \& Wimmer, H. (2006). Evidence for a dysfunction of left posterior reading areas in German dyslexic readers. Neuropsychologia, 44, 1822-1832.

Law, J. M., Wouters, J., \& Ghesquière, P. (2015). Morphological awareness and its role in compensation in adults with dyslexia. Dyslexia, 21, 254-272.

Lefavrais, P. (2005). L'Alouette-R. Paris: Les Editions du Centre de Psychologie Appliquée.

Maris, E., \& Oostenveld, R. (2007). Nonparametric statistical testing of EEG- and MEG-data. Journal of Neuroscience Methods, 164, 177-190.

Martin, J., Frauenfelder, U. H., \& Colé, P. (2013). Morphological awareness in dyslexic university students. Applied Psycholinguistics, 1-21.

Nolte, G. (2003). The magnetic lead field theorem in the quasistatic approximation and its use for magnetoencephalography forward calculation in realistic volume conductors. Physics in Medicine and Biology, 48, 3637-3652.

Norton, E. S., Beach, S. D., \& Gabrieli, J. D. E. (2014). Neurobiology of dyslexia. Current Opinion in Neurobiology, 30, 73-78.

Oostenveld, R., Fries, P., Maris, E., \& Schoffelen, J. M. (2011). FieldTrip: Open source software for advanced analysis of MEG, EEG, and invasive electrophysiological data. Computational Intelligence and Neuroscience, 2011, 156869.

Paulesu, E., Danelli, L., \& Berlingeri, M. (2014). Reading the dyslexic brain: Multiple dysfunctional routes revealed by a new meta-analysis of PET and PMRI activation studies. Frontiers in Human Neuroscience, 8, 830.

Price, C. J. (2012). A review and synthesis of the first 20 years of PET and fMRI studies of heard speech, spoken language and reading. NeuroImage, 62, 816-847.

Price, C. J., \& Devlin, J. T. (2011). The interactive account of ventral occipitotemporal contributions to reading. Trends in Cognitive Sciences, 15, 246-253.

Pugh, K. R., Mencl, W. E., Shaywitz, B. A., Shaywitz, S. E., Fulbright, R. K., Constable, R., et al. (2000). The angular gyrus in developmental dyslexia: Task-specific differences in functional connectivity within posterior cortex. Psychological Science, 11, 51-56.

Pylkkänen, L., \& Marantz, A. (2003). Tracking the time course of word recognition with MEG. Trends in Cognitive Sciences, 7, 187-189.

Quémart, P., \& Casalis, S. (2013). Visual processing of derivational morphology in children with developmental dyslexia: Insights from masked priming. Applied Psycholinguistics, 1-32.

Rastle, K., \& Davis, M. H. (2008). Morphological decomposition based on the analysis of orthography. Language and Cognitive Processes, 23, 942-971.

Raven, J., Court, J., \& Raven. (1995). Standard Progressive Matrices Series A, B, C, D, E (revised 1956). Paris: Editions techniques et psychotechniques.

Richlan, F. (2012). Developmental dyslexia: Dysfunction of a left hemisphere reading network. Frontiers in Human Neuroscience, 6, 120.

Richlan, F., Kronbichler, M., \& Wimmer, H. (2011). Meta-analyzing brain dysfunctions in dyslexic children and adults. NeuroImage, 56, 1735-1742.

Rüsseler, J., Becker, P., Johannes, S., \& Münte, T. F. (2007). Semantic, syntactic, and phonological processing of written words in adult developmental dyslexic readers: An eventrelated brain potential study. BMC Neuroscience, 8, 52.

Sahin, N. T., Pinker, S., Cash, S. S., Schomer, D., \& Halgren, E. (2009). Sequential processing of lexical, grammatical, and phonological information within Broca's area. Science, 326, 445-449.

Salmelin, R., Service, E., Kiesilä, P., Uutela, K., \& Salonen, O. (1996). Impaired visual word processing in dyslexia revealed with magnetoencephalography. Annals of Neurology, 40, 157-162.

Saur, D., Kreher, B. W., Schnell, S., Kümmerer, D., Kellmeyer, P., Vry, M. S., et al. (2008). Ventral and dorsal pathways for language. Proceedings of the National Academy of Sciences of the United States of America, 105, 18035-18040.

Shaywitz, S. E., \& Shaywitz, B. A. (2005). Dyslexia (specific reading disability). Biological Psychiatry, 57, 1301-1309.

Shaywitz, S. E., Shaywitz, B. A., Pugh, K. R., Fulbright, R. K. Constable, R. T., Mencl, W. E., et al. (1998). Functional disruption in the organisation of the brain for reading in dyslexia. Proceedings of the National Academy of Sciences of the United States of America, 95, 2636-2641.

Snowling, M. J. (2000). Dyslexia. Oxford, England: Blackwell Publishing.

Solomyak, O., \& Marantz, A. (2010). Evidence for early morphological decomposition in visual word recognition. Journal of Cognitive Neuroscience, 22, 2042-2057.

Sprenger-Charolles, L., Colé, P., Béchennec, D., \& KipfferPiquard, A. (2005). French normative data on reading and related skills from EVALEC, a new computerized battery of tests (end Grade 1, Grade 2, Grade 3, and Grade 4). European Review of Applied Psychology, 55, 157-186.

Stanovich, K. E. (1980). Toward an interactive-compensatory model of individual differences in the development of reading fluency. Reading Research Quarterly, 16, 32-71.

Tzourio-Mazoyer, N., Landeau, B., Papathanassiou, D., Crivello, F., Etard, O., Delcroix, N., et al. (2002). Automated anatomical labeling of activations in SPM using a macroscopic anatomical parcellation of the MNI MRI single-subject brain. NeuroImage, 15, 273-289.

van Been, B. D., van Drongelen, W., Yuchtman, M., \& Suzuki, A. (1997). Localization of brain electrical activity via linearly constrained minimum variance spatial filtering. IEEE Transactions on Biomedical Engineering, 44, 867-880.

Vandermosten, M., Boets, B., Poelmans, H., Sunaert, S., Wouters, J., \& Ghesquière, P. (2012). A tractography study in dyslexia: Neuroanatomic correlates of orthographic, phonological and speech processing. Brain, 135, 935-948. 
Vinckier, F., Dehaene, S., Jobert, A., Dubus, J. P., Sigman, M., \& Cohen, L. (2007). Hierarchical coding of letter strings in the ventral Stream: Dissecting the inner organization of the visual word-form system. Neuron, 55, 143-156.

Warmington, M., Stothard, S. E., \& Snowling, M. J. (2013). Assessing dyslexia in higher education: The York adult assessment battery-revised. Journal of Research in Special Educational Needs, 13, 48-56.

Whiting, C., Shtyrov, Y., \& Marslen-Wilson, W. (2015). Real-time functional architecture of visual word recognition. Journal of Cognitive Neuroscience, 27, 246-265.

Woodhead, Z. V., Barnes, G. R., Penny, W., Moran, R., Teki, S., Price, C. J., et al. (2014). Reading front to Back: MEG evidence for early feedback effects during word recognition. Cerebral Cortex, 24, 817-825.

Woodhead, Z. V., Penny, W., Barnes, G. R., Crewes, H., Wise, R. J., Price, C. J., et al. (2013). Reading therapy strengthens top-down connectivity in patients with pure alexia. Brain, 136, 2579-2591.

Zhao, L., Chen, C., Shao, L., Wang, Y., Xiao, X., Chen, C., et al. (2016). Orthographic and phonological representations in the fusiform cortex. Cerebral Cortex, 1-14. http://dx.doi.org/ 10.1093/cercor/bhw300.

Zou, L., Packard, J. L., Xia, Z., Liu, Y., \& Shu, H. (2016). Neural correlates of morphological processing: evidence from Chinese. Front Hum Neurosci., 9, 714. 